\title{
The direct radiative effect of biomass burning aerosols over southern Africa
}

\author{
S. J. Abel ${ }^{1,2}$, E. J. Highwood ${ }^{1}$, J. M. Haywood ${ }^{2}$, and M. A. Stringer ${ }^{1}$ \\ ${ }^{1}$ Department of Meteorology, University of Reading, UK \\ ${ }^{2}$ Met Office, Exeter, UK \\ Received: 8 November 2004 - Published in Atmos. Chem. Phys. Discuss.: 7 March 2005 \\ Revised: 1 July 2005 - Accepted: 4 July 2005 - Published: 4 August 2005
}

\begin{abstract}
A multi-column radiative transfer code is used to assess the direct radiative effect of biomass burning aerosols over the southern African region during September. The horizontal distribution of biomass smoke is estimated from two sources; i) General Circulation Model (GCM) simulations combined with measurements from the Aerosol Robotic Network (AERONET) of Sun photometers; ii) data from the Moderate resolution Imaging Spectrometer (MODIS) satellite. Aircraft and satellite measurements are used to constrain the cloud fields, aerosol optical properties, vertical structure, and land surface albedo included in the model. The net regional direct effect of the biomass smoke is -3.1 to $-3.6 \mathrm{Wm}^{-2}$ at the top of atmosphere, and -14.4 to $-17.0 \mathrm{Wm}^{-2}$ at the surface for the MODIS and GCM distributions of aerosol. The direct radiative effect is shown to be highly sensitive to the prescribed vertical profiles and aerosol optical properties. The diurnal cycle of clouds and the spectral dependency of surface albedo are also shown to play an important role.
\end{abstract}

\section{Introduction}

Atmospheric aerosols provide one of the largest uncertainties in our understanding of how human beings are continually altering the Earth's climate. Aerosols act to modify the radiative balance of the climate system by scattering and absorbing radiation (the direct effect), and by altering the lifetime and radiative properties of clouds (the indirect effect). Both effects are believed to lead to a reduction in the global annual mean surface temperature, thereby suppressing the warming that is attributed to anthropogenic greenhouse gases (e.g. Boucher and Haywood, 2001; IPCC, 2001).

Correspondence to: S. J. Abel

(steven.abel@metoffice.gov.uk)
Biomass burning has been recognized as a significant contributor to the burden of aerosols in continental tropical regions (Crutzen and Andreae, 1990), and the corresponding radiative impacts are often much more dramatic than that from greenhouse gases on local and regional scales (e.g. Ross et al., 1998; Ichoku et al., 2003; Keil and Haywood, 2003). However, quantifying the impact of biomass burning aerosols on both regional and global climate is problematic, due to the complexity in the aerosols chemical, physical, and optical properties, their spatial and temporal variability in the atmosphere, and the difficulty in characterizing their interaction with clouds. This is highlighted by the factor of three uncertainty and the very low level of scientific understanding assigned by IPCC (2001) for the global annual mean direct radiative forcing from biomass burning aerosols.

Detailed in situ measurements and satellite based retrievals have the potential to address some of these uncertainties, enabling the representation of the radiative effects of aerosols in climate models to be improved. This study incorporates satellite and in situ based measurements of biomass burning aerosols into a multi-column radiative transfer code, to assess their direct radiative effect over the southern African region during September when anthropogenic burning activities are widespread. Sensitivity studies are then performed with the aim of highlighting the important parameters that need to be targeted by future observations and well represented in climate models in order to reduce the current uncertainties in the direct radiative effect of biomass burning aerosols.

\section{Experimental setup}

\subsection{Radiative transfer model}

A multi-column version of the Edwards-Slingo radiative transfer code (Edwards and Slingo, 1996) is used to examine the short-wave direct radiative effect of southern African

(C) 2005 Author(s). This work is licensed under a Creative Commons License. 
Table 1. Summary of the number of AERONET stations, months, and days in the climatology during the observation period June 1995September 2003 for each month of the year. Also shown is the factor by which the total aerosol optical depth in the GCM of Tegen et al. (1997) needs to be increased to obtain a reasonable agreement with AERONET measurements.

\begin{tabular}{lcccccccccccc}
\hline & Jan. & Feb. & March & Apr. & May & June & July & Aug. & Sept. & Oct. & Nov. & Dec. \\
\hline Stations & 7 & 8 & 7 & 6 & 8 & 13 & 11 & 18 & 20 & 13 & 10 & 9 \\
Months & 16 & 18 & 17 & 14 & 17 & 23 & 22 & 34 & 36 & 27 & 25 & 19 \\
Days & 281 & 258 & 260 & 287 & 373 & 445 & 435 & 685 & 706 & 461 & 367 & 299 \\
Factor & 2.7 & 3.1 & 2.5 & 2.2 & 1.3 & 0.9 & 1.1 & 1.8 & 2.5 & 3.4 & 1.8 & 2.2 \\
\hline
\end{tabular}

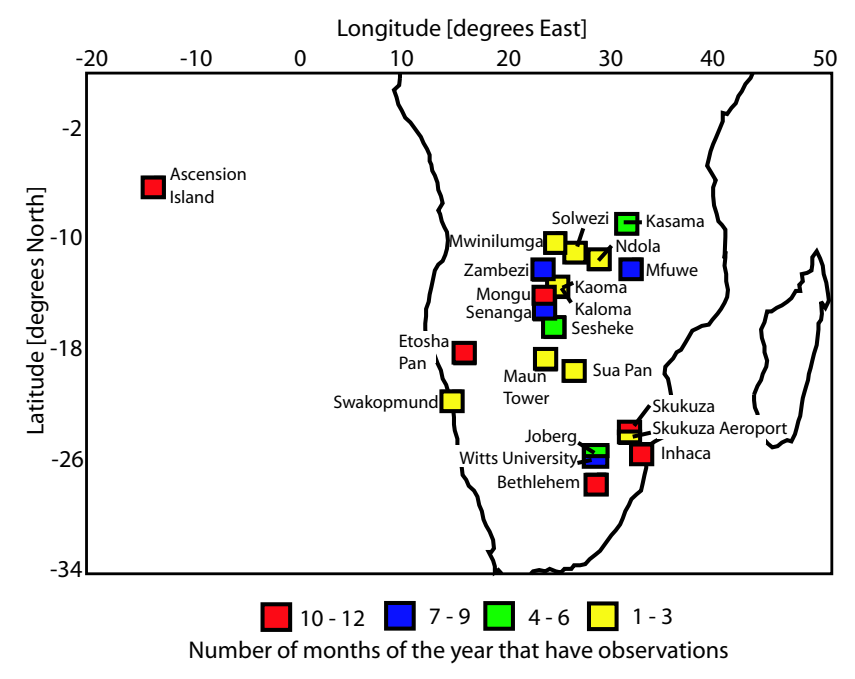

Fig. 1. AERONET stations in southern Africa that are used to build up a climatology of monthly mean aerosol optical depth. The number of months of the year that data are available is also shown for each station.

biomass burning aerosols. Calculations are performed using the two-stream delta-Eddington approximation at a spectral resolution of 220 bands, encompassing the wavelength range 0.2 to $10 \mu \mathrm{m}$, with the majority of bands situated in the visible and near infra-red part of the spectrum. The horizontal resolution of the model was set at $4 \times 5^{\circ}$, and the vertical resolution at 33 levels. The long-wave effect of the biomass burning aerosol is neglected and is likely to be small due to the strong wavelength dependence of the aerosol extinction coefficient (Haywood et al., 2003a).

3-D fields of any radiatively active gaseous absorbers, aerosols, and clouds, and a 2-D surface pressure and Lambertian surface albedo field can be prescribed in the model. In this study, the vertical profiles of temperature, pressure, and gaseous absorbers were held constant at every grid box. The tropical climatology of McClatchey et al. (1972) was used for temperature, $\mathrm{O}_{3}$, and $\mathrm{H}_{2} \mathrm{O}(\mathrm{g})$. Other greenhouse gases included in the model were $\mathrm{N}_{2} \mathrm{O}, \mathrm{CH}_{4}, \mathrm{CO}_{2}$, and $\mathrm{O}_{2}$. The mixing ratio data for these gases were taken from Cofer et al. (1996) and IPCC (2001) and were assumed to be well mixed throughout the atmosphere. Although elevated levels of gaseous absorbers such as $\mathrm{CH}_{4}$ will exist in the biomass plume, the impact on the short-wave is negligible. The distributions of biomass burning aerosol, cloud, and surface albedo included in the model are discussed in subsequent sections.

\subsection{Horizontal distribution of aerosol}

Two independent sources are used to simulate the horizontal distribution of biomass burning aerosols over southern Africa; i) General circulation model (GCM) calculations that utilize transport models of various aerosol species (Tegen et al., 1997); ii) the Moderate resolution Imaging Spectrometer (MODIS) satellite retrieval of aerosol optical depth (Kaufman et al., 1997; Tanré et al., 1997; Ichoku et al., 2003).

\subsubsection{Model estimate of aerosol optical depth}

The GCM model data of Tegen et al. (1997) consists of a global distribution of the monthly mean aerosol optical depth at a wavelength of $0.55 \mu \mathrm{m}\left(\tau_{\lambda=0.55 \mu \mathrm{m}}\right)$, for several aerosol species based on transport models of soil dust (Tegen and Fung, 1995), sea salt (Tegen et al., 1997), sulfate (Chin et al., 1996), and organic carbon (OC) and black carbon (BC) (Liousse et al., 1996) aerosols. The data is output at a horizontal resolution of $4 \times 5^{\circ}$. The carbonaceous component $(\mathrm{OC}+\mathrm{BC})$ characterizes aerosols emitted from natural sources (e.g. direct emission of OC from plants), fossil fuel burning, domestic fires (e.g. wood/charcoal/dung), agricultural fires (e.g. wheat/corn/rice), and savanna and forest burning. For this study, the contribution by biomass burning aerosols to the carbonaceous component over southern Africa during the dry season are assumed to dominate over emissions from natural and fossil fuel sources, allowing the spatial distribution of the biomass smoke to be determined.

A climatology of ground based observations from the Aerosol Robotic Network (AERONET) of Sun and sky scanning spectral radiometers (Holben et al., 1998) over southern Africa is compiled to assess the accuracy of the GCM calculations. The cloud screened, calibrated, and manually inspected Level 2.0 AERONET data (Smirnov et al., 2000) covering the time period of June 1995-September 2003 is 

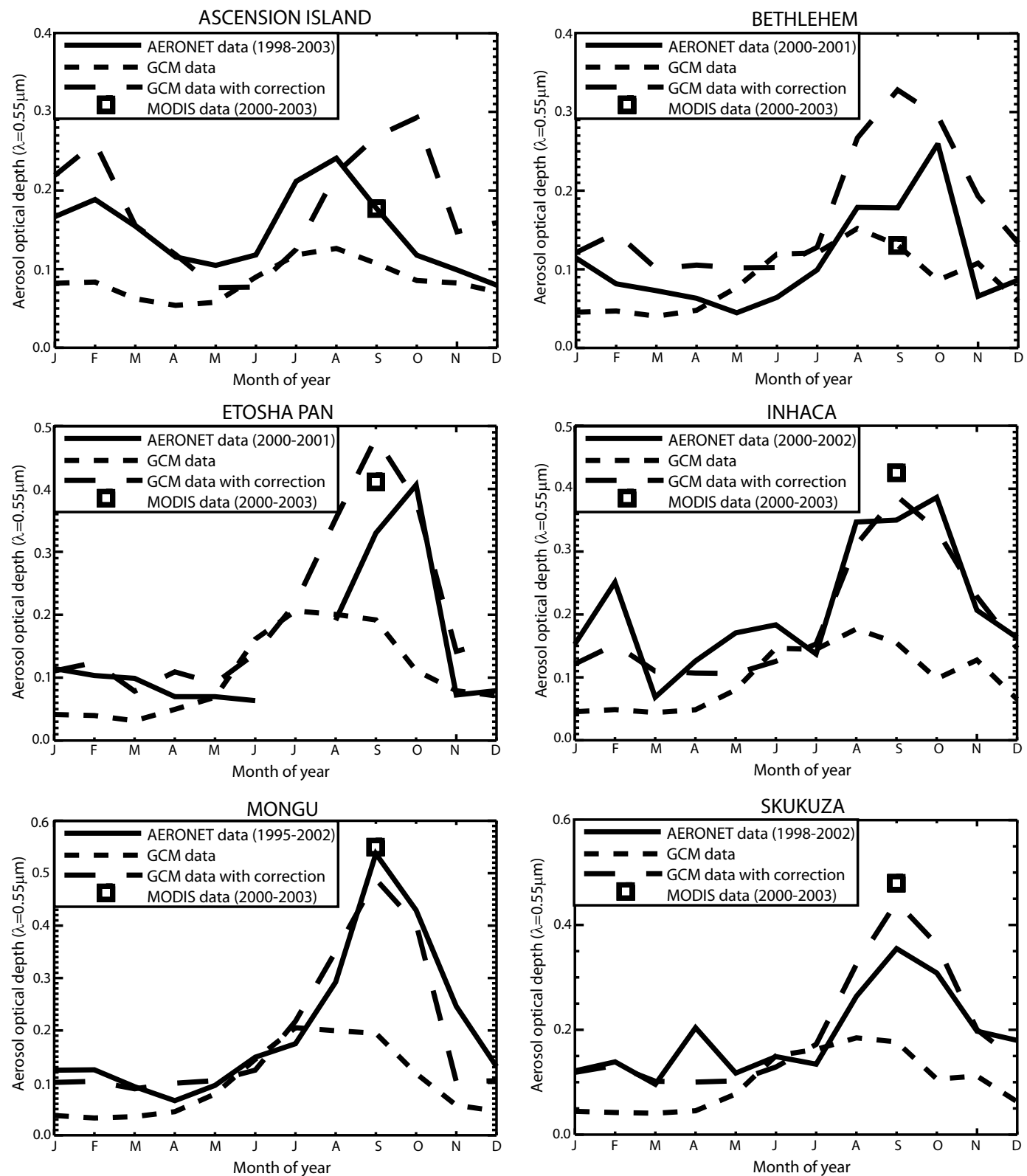

Fig. 2. Comparison of the monthly mean column integrated aerosol optical depth at $0.55 \mu \mathrm{m}$ from the GCM of Tegen et al. (1997) with values measured at 6 AERONET sites. The years where the AERONET data was obtained is indicated on the individual plots. Also shown is the monthly mean value with a correction factor applied to the GCM data derived from a linear fit to the AERONET measurements (see Table 1), and the mean MODIS aerosol optical depth $\left(1 \times 1^{\circ}\right)$ for September (2000-2003 average) co-incident with the AERONET site.

used. A daily averaged $\tau_{\lambda}$ is initially compiled at each AERONET site, and then the monthly mean computed. Only days where at least three individual measurements are available are included in the climatology. This process resulted in a total of 4857 daily and 268 monthly averaged values covering the 22 AERONET stations that had data available in the observation period considered, the location of which are indicated in Fig. 1. Table 1 summarizes the observational statistics for each month. It is clear that August and September contain the greatest number of observations. This is a result of some temporary stations only taking measurements during the intensive Southern African Regional Science Initiative (SAFARI 2000) field campaign. The spatial distribution of observations is poorest for April, with only 6 stations included in the climatology.

To allow for a direct comparison with the GCM results, a third order polynomial fit is used to interpolate the AERONET data to a wavelength of $0.55 \mu \mathrm{m}$ from the reported wavelengths of $0.34,0.38,0.44,0.50,0.67,0.87$, and $1.02 \mu \mathrm{m}$. For all months and stations, the coefficient of determination $\left(\mathrm{R}^{2}\right)$ for the fit exceeded 0.95 . Figure 2 shows a comparison of the total column integrated optical depth 
from the six AERONET stations that have data for at least 11 months of the year, with the GCM data in the grid box co-incident with each station. The AERONET data at Ascension Island, some $2500 \mathrm{~km}$ off the coast of southern Africa, has a peak in August, indicating that significant amounts of biomass burning aerosol are transported large distances over the southern Atlantic Ocean during the dry season, as was measured onboard the Met Office C-130 aircraft during SAFARI 2000 (Haywood et al., 2003a). The other stations on the southern African continent show large increases in $\tau_{\lambda=0.55 \mu \mathrm{m}}$ from the background values for the period of $\mathrm{Au}-$ gust to October when biomass burning is prevalent. It is clear that the GCM results severely under predict the $\tau_{\lambda=0.55 \mu \mathrm{m}}$ at all stations, especially in the dry season. The model also appears to initiate the biomass burning season in May to June, whereas the observations suggest it occurs closer to July. Satellite derived burned area maps also suggest that July is more appropriate for the areas where the continental based AERONET stations used in this study are located, although areas to the north and west of the AERONET sites are subject to burning from May onwards (Barbosa et al., 1999).

In order to quantify the underestimation in the model optical depth, a correction factor specific to each month is derived from a linear fit of the GCM $\tau_{\lambda=0.55 \mu \mathrm{m}}$ to that measured at the AERONET stations using all of the data in the climatology. Table 1 lists the correction factors for each month. The model appears to predict the column integrated optical depth to within $\pm 10 \%$ in the months of June and July, although this may be due to the early initiation of the biomass burning cycle. During the burning season the model under

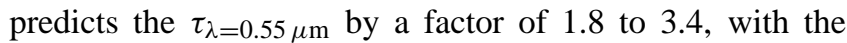
largest error in September and October. Figure 2 also includes the GCM data multiplied by the derived correction factors and the MODIS satellite data for September. The improvement in the model data with respect to the AERONET and satellite observations in both the magnitude and the seasonal cycle of $\tau_{\lambda=0.55 \mu \mathrm{m}}$ is evident, suggesting that the correction factors are realistic.

However, to model the radiative impact of the biomass smoke alone, the fraction of aerosol in the column that is attributed to the background aerosol needs to be removed. Following the methodology of Remer et al. (2002a), it is assumed that the GCM of Tegen et al. (1997) models the background aerosol components (sea salt + soil dust + sulfate) well in the dry season, and that the underestimation in the column integrated optical depth is entirely due to the model producing low amounts of biomass burning aerosol. To compensate for the underestimation of the biomass burning aerosol $\tau_{\lambda=0.55 \mu \mathrm{m}}$ in September (peak of burning season) the smoke component in the GCM data is boosted by a factor of 4.4 to reach agreement with the AERONET climatology. This translates to a mean and standard deviation column fraction of biomass smoke of $84 \pm 12 \%$. The derived column fraction is in agreement with the C-130 aircraft measurements over the south Atlantic (Osborne et al., 2004). However, the assumption that the background aerosol is modeled well in the GCM is highly uncertain, especially when the GCM also underestimates the $\tau_{\lambda=0.55 \mu \mathrm{m}}$ in months where biomass burning is uncommon (e.g. by a factor of 3.1 in February). Until global aerosol models can adequately reproduce observed distributions of aerosol, estimating the column contribution of aerosol by type is problematic.

\subsubsection{MODIS satellite estimate of aerosol optical depth}

The monthly mean column integrated aerosol optical depth for September (2000-2003 average) retrieved with the MODIS instrument onboard the Terra satellite and reported in the MOD08 Level-3 global atmospheric product at a wavelength of $0.55 \mu \mathrm{m}$, is also used to estimate the spatial distribution of the biomass burning aerosol. The monthly aerosol product results from an average of the daily Level-2 MOD04 $10 \times 10 \mathrm{~km}$ resolution aerosol product aggregated to a spatial resolution of $1 \times 1^{\circ}$ (King et al., 2003). A brief overview of the retrieval algorithm is now given.

The underlying assumption in the MODIS aerosol retrieval is that the up-welling reflectance measured at the top of the atmosphere (TOA) is given by the sum of the surface and atmospheric components in the solar wavelength range. The atmospheric component of reflectance contains information about molecular scattering, clouds, and aerosols. For the aerosol retrieval, cloud pixels are screened out using the MODIS cloud mask (Platnick et al., 2003) and aerosol properties are determined only in clear skies. To remove the surface contribution, different procedures are then applied when retrieving aerosol properties over land and ocean as a result of the more complex characteristics of the land surface reflectance. Over ocean the surface contribution to the TOA reflectance is relatively small and is parameterized in the operational retrieval algorithm (Ichoku et al., 2003). Over land the surface reflectance is estimated using the $2.13 \mu \mathrm{m}$ channel which is largely transparent to anthropogenic aerosol (large coarse mode particles are likely to degrade the accuracy). This is then used to estimate the surface reflectance in other channels. However, the empirical relation used to estimate the surface reflectance at other wavelengths is only applicable to dark dense vegetation or dark soils (Kaufman et al., 1997) and aerosol retrievals over bright surfaces such as deserts are not made.

Once the surface characteristics are determined the retrieval then uses look-up tables based on detailed radiative transfer calculations that include variable $\tau_{\lambda}$, solar zenith angle (SZA), satellite viewing angles, and various aerosol models to obtain agreement between the measured and modeled reflectances. Nine aerosol models are used in the ocean algorithm (4 fine modes, 5 coarse modes) and are not restricted to geographical location (Tanré et al., 1997), whereas the operational land algorithm contains only 3 aerosol models (2 fine modes, 1 coarse mode), of which an a-priori assumption of any fine mode contribution is determined solely on 

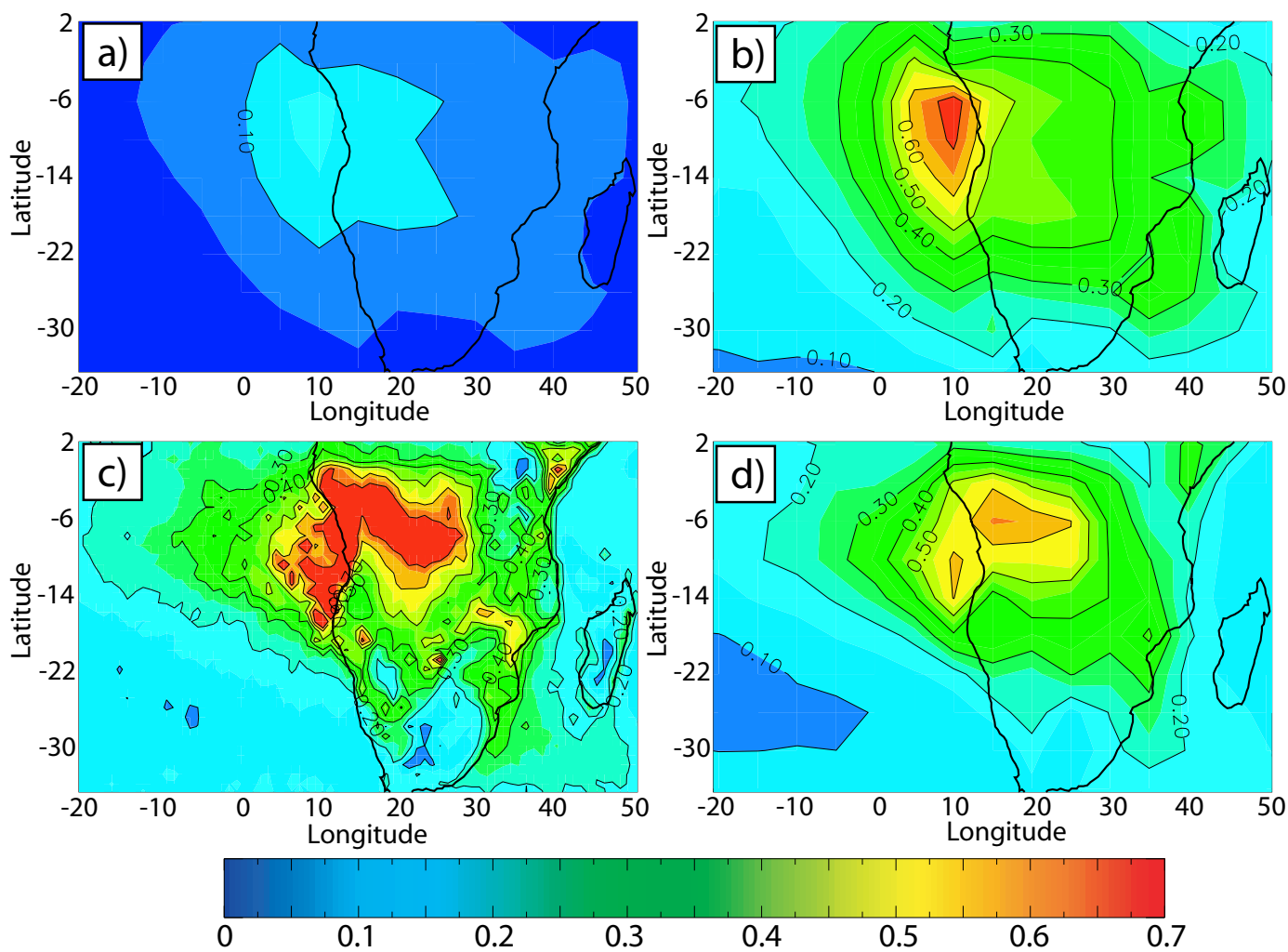

Fig. 3. Monthly mean aerosol optical depth for September at a wavelength of $0.55 \mu \mathrm{m}$ for (a) OC+BC component in the GCM; (b) OC+BC component in GCM increased by a factor of 4.4 as derived from comparison with AERONET measurements; (c) MODIS total column (2000-2003 average); (d) MODIS data aggregated to the GCM resolution and $\times 0.84$ to estimate the biomass burning aerosol fraction. The MODIS data is linearly interpolated to missing data regions over arid land areas where the surface reflectance exceeds the threshold value required for the aerosol retrieval.

geographical location and season (Kaufman et al., 1997). During the biomass burning season over southern Africa, the aerosol model used assumes a fine fraction single scattering albedo $\left(\omega_{0 \lambda}=0.67 \mu \mathrm{m}\right)$ of 0.90 . This is in reasonable agreement with the C-130 aircraft measurements taken in the aged regional haze during SAFARI 2000 (Haywood et al., 2003a), but significantly higher than the measurements taken near source regions (Abel et al., 2003; Haywood et al., 2003a). The lower $\omega_{0}$ near source regions is likely to lead to an underestimation in the MODIS retrieved optical depth in southern Africa (Ichoku et al., 2003). However, the prelaunch estimates for the retrieval accuracy of $\Delta \tau= \pm 0.05 \pm 0.05 \tau$ at a wavelength of $0.55 \mu \mathrm{m}$ over ocean (Tanré et al., 1997) and $\Delta \tau_{\lambda}= \pm 0.05 \pm 0.20 \tau_{\lambda}$ over land (Kaufman et al., 1997) have been shown to be reasonable (Chu et al., 2002; Remer et al., 2002b).

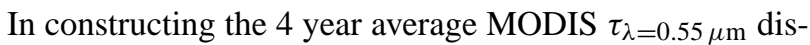
tribution for this study, the data was linearly interpolated to "data-missing" regions over land where the surface reflectance is too high for the retrieval algorithm. The data was then aggregated to the same resolution as the GCM and multiplied by the biomass smoke column fraction of $84 \%$ de- rived in Sect. 2.2.1. As discussed previously, estimating the contribution of biomass smoke is highly problematic and the errors associated with the value of $84 \%$ need to be treated as an additional uncertainty in the presented model calculations.

\subsubsection{Comparison of the model and MODIS aerosol optical depth}

Figure 3 shows the spatial distribution of the monthly mean

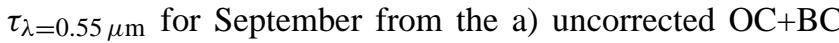
component in the GCM results of Tegen et al. (1997); b) the $\mathrm{OC}+\mathrm{BC}$ component boosted by the correction factor of 4.4 derived from the comparison with the AERONET climatology; c) the MODIS total column integrated value; d) the MODIS data multiplied by $84 \%$ to estimate the biomass burning aerosol component and aggregated to the GCM resolution. The transition between the ocean and land retrievals of aerosol in the monthly mean MODIS data is reasonably consistent even though significant differences exist between the retrieval algorithms over land and ocean.

The under estimation of the aerosol optical depth in the uncorrected GCM data is evident, with values over southern Africa being significantly lower than in the MODIS satellite 
Table 2. Optical properties for fresh and aged biomass burning aerosols at selected wavelengths $(\mu \mathrm{m})$.

\begin{tabular}{|c|c|c|c|c|c|c|c|c|c|}
\hline \multirow[t]{2}{*}{ Aerosol age } & \multicolumn{3}{|c|}{$\omega_{0}$} & \multicolumn{3}{|c|}{$g$} & \multicolumn{3}{|c|}{$k_{e}\left(\mathrm{~m}^{2} \mathrm{~g}^{-1}\right)$} \\
\hline & $\lambda=0.45$ & $\lambda=0.55$ & $\lambda=0.70$ & $\lambda=0.45$ & $\lambda=0.55$ & $\lambda=0.70$ & $\lambda=0.45$ & $\lambda=0.55$ & $\lambda=0.70$ \\
\hline Fresh & 0.86 & 0.84 & 0.81 & 0.62 & 0.56 & 0.49 & 3.27 & 2.22 & 1.41 \\
\hline Regional haze & 0.91 & 0.89 & 0.87 & 0.66 & 0.60 & 0.52 & 4.82 & 3.37 & 2.12 \\
\hline
\end{tabular}

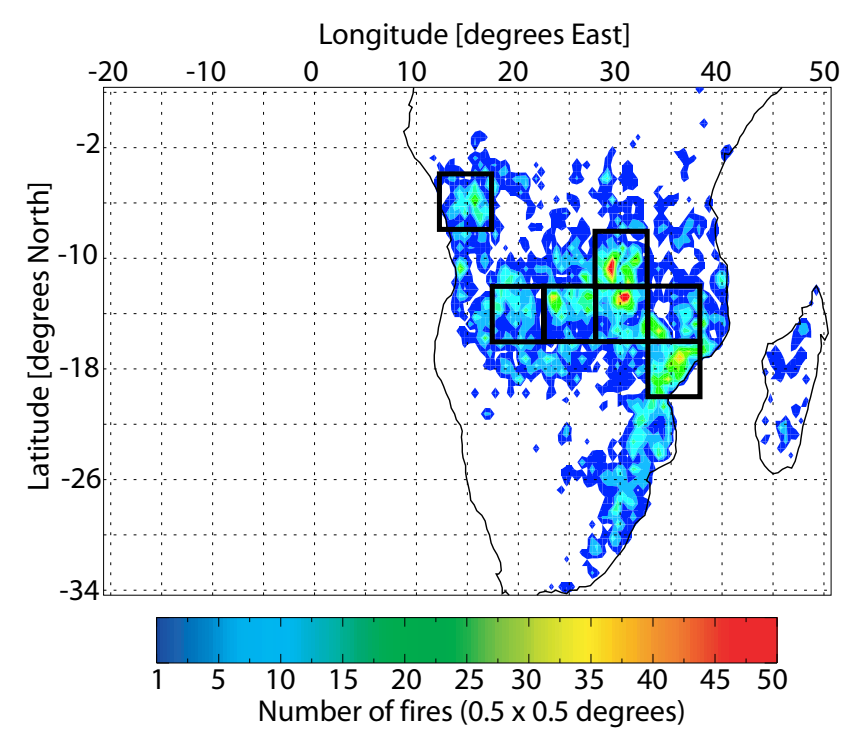

Fig. 4. Fire pixels for September (1998-2002 average) retrieved from the VIRS instrument onboard the TRMM satellite. The data has been corrected for multiple satellite overpasses and missing observations (Giglio et al., 2003). The black squares show the grid boxes used in the modeling work in this study where the most frequent burning occurs (total fire counts $\geq 500$ ).

retrieval. This may be the result of an underestimation in the source strength of the biomass burning aerosol, a result that is a common feature in many global aerosol models (Kinne et al., 2003). Furthermore, the emission inventories used in the model are from the early 1980s. Emission strengths may certainly have increased in the years where the satellite data is taken (2000-2003). Deficiencies in how the model transports the aerosol may also contribute to the low optical depths, although such assessments are beyond the scope of this article. Correcting the GCM data with the factor derived from the AERONET climatology brings the spatial pattern into much better agreement with the MODIS distribution. However, whereas there is a single peak off the western coast of southern Africa in the model data, the MODIS data has a secondary peak inland. Over oceanic regions the corrected GCM distribution tends to produce higher values of aerosol optical depth than the remotely sensed data, especially off the eastern coast of Africa. The higher values are likely to result from the unrealistic humidity dependence in the OC component of the aerosol in the model data. In calculating the $\tau_{\lambda=0.55 \mu \mathrm{m}}$ from the model generated columnar mass, Tegen et al. (1997) use a specific extinction coefficient of OC aerosol that is a factor of 1.7 higher over oceanic regions than over land to account for hygroscopic growth of the aerosol. Recent in-situ measurements from SAFARI 2000 show that biomass burning aerosol is only moderately affected by relative humidity (Magi and Hobbs, 2003), suggesting that the large increase in $\tau_{\lambda=0.55 \mu \mathrm{m}}$ in the model data over oceans is unrealistic. The sensitivity of the direct radiative effect of the biomass burning aerosol over southern Africa to the two spatial distributions of smoke (Figs. $3 b$ and d) is examined in Sect. 3.1.

\subsection{Aerosol optical properties}

Mie theory is used to model the wavelength dependent optical properties of the biomass burning aerosol in both source regions that are heavily influenced by fresh smoke, and in the aged regional haze. This is achieved by fitting a series of three log-normals to the aerosol size distribution measured onboard the Met Office C-130 aircraft during the SAFARI 2000 field campaign in a fresh smoke plume (flight a790) and in aged smoke off the coast of Namibia (flight a791) (Haywood et al., 2003a). Suitable refractive indices were chosen to simulate the single scattering albedo $\left(\omega_{0 \lambda}=0.55 \mu \mathrm{m}\right)$ calculated from direct measurements of the aerosol scattering and absorption (Abel et al., 2003; Haywood et al., 2003a). A complex refractive index of $1.54-0.024 i$ and $1.54-0.018 i$ at a wavelength of $0.55 \mu \mathrm{m}$ is used for the fresh and aged smoke respectively. A particle density of $1.35 \mathrm{gcm}^{-3}$ is assumed for both the fresh and aged aerosol (Haywood et al., 2003a). Including the optical properties of biomass burning aerosol modeled in this manner into a radiative transfer code has been shown to give excellent agreement with independent measurements of the sky radiance (Haywood et al., 2003b). Table 2 summarizes the modeled $\omega_{0}$, asymmetry parameter $(g)$, and the specific extinction coefficient $\left(k_{e}\right)$ at selected wavelengths. The wavelength dependence in $\omega_{0}$ of the fresh and aged aerosol is very similar to that derived from AERONET almucantar measurements in regions subject to intense burning and more aged smoke in southern Africa (Eck et al., 2003). The effect of hygroscopic growth 
is neglected as the effect on the optical properties is minimal (Magi and Hobbs, 2003) at the low relative humidities measured in the biomass burning aerosol plume, and so the measured quasi-dry aerosol optical properties are used.

To identify the most active regions of burning over southern Africa, the multi-year active fire data set derived from the Visible and Infrared Scanner (VIRS) instrument on the Tropical Rainfall Measuring Mission (TRMM) satellite is used. The strong emission of mid infra-red radiation from fires is exploited to detect a fire from the VIRS instrument, and a detailed description of the retrieval algorithm and performance is given in Giglio et al. (2003). Figure 4 shows the mean fire counts for southern Africa in September (1998-2002 average). It is clear that the majority of fire activity in September occurs in a band between latitudes of -2 and $-18^{\circ} \mathrm{N}$, although the east coast of southern Africa undergoes significant burning at more southerly latitudes. Figure 4 also shows the grid boxes where the total fire count exceeds 500, indicating the areas where biomass burning is most prevalent and the optical properties of fresh biomass burning aerosol are likely to dominate over the aged regional haze and should be included in the multi-column radiative transfer model. This is supported by aircraft observations downwind of a biomass fire in southern Africa that show a rapid evolution in the optical properties of the aerosol in the first few hours subsequent to emission (Abel et al., 2003). By the time the aerosol is advected away from the burning region, the optical properties measured in the aged regional haze will be more suitable. Further, AERONET measurements of $\omega_{0}$ from SAFARI 2000 show values of 0.84 to 0.85 in the areas where local biomass burning is common, with higher values in areas away from the source regions (Eck et al., 2003). It should be noted that the threshold of 500 fires in a grid box to define the areas with greatest fire activity and thus where fresh aerosol properties are used is somewhat arbitrary, especially since the fire count data is likely to underestimate the total number of fires (Giglio et al., 2003). However, the sensitivity of the direct radiative effect over southern Africa to variations in the threshold value is investigated in Sect. 3.2.

\subsection{Horizontal distribution of cloud}

Monthly mean data from the MODIS Terra satellite is employed to include cloud into the multi-column radiative transfer model using the $1 \times 1^{\circ}$ MOD08 Level-3 global atmospheric product (King et al., 2003; Platnick et al., 2003). Figure 5 shows the horizontal distribution and histograms of the water cloud optical depth $\left(\tau_{\text {cloud }}\right)$ and droplet effective radius $\left(r_{e f f}\right)$ for September (2000-2003 mean). Also shown are the water and ice cloud fractions over the southern African region.

The spatial distribution of the water cloud $\tau_{\text {cloud }}$ (Fig. 5a) shows values ranging from approximately $6-13$ off the coast of Namibia and Angola in September, where values of $\tau_{\text {cloud }}$ ranging from 1-12 were inferred from the C-130 aircraft measurements of cloud liquid water path and $r_{e f f}$ (Haywood et al., 2004). Higher $\tau_{\text {cloud }}$ occurs when cloud forms over land, although the histogram reveals a peak value of 8 (mean=9, $\sigma=3$ ) over the whole of the southern African region. The histogram of water cloud $r_{\text {eff }}$ (Fig. 5b) peaks at $13 \mu \mathrm{m}$ (mean $=14 \mu \mathrm{m}, \sigma=3 \mu \mathrm{m})$. This value is somewhat higher than that measured on the C-130 aircraft during SAFARI 2000, with Keil and Haywood (2003) reporting a cloud top $r_{e f f}$ of $7.4 \pm 3.6 \mu \mathrm{m}, 7.4 \pm 3.1 \mu \mathrm{m}$, and $7.8 \pm 1.1 \mu \mathrm{m}$ for three flights off the coast Namibia and Angola. This apparent discrepancy highlights the difficulty in comparing monthly averaged fields from satellite data with point measurements made in situ at a single instant in time. The water cloud fraction (Fig. 5 c) histogram peaks at $38 \%$ (mean $=41 \%, \sigma=21 \%$ ), although much larger values in excess of 60-70\% can be seen off the coast of Namibia and Angola where a semi-permanent stratocumulus cloud sheet is present. Furthermore, it is clear from the spatial distribution plot that the majority of the land mass in southern Africa is persistently cloud free during September, with the exception being near some coastal areas. The ice cloud fraction (Fig. 5d) shows a very different distribution to the water cloud. The histogram peaks at $0 \%$ (mean $=8 \%, \sigma=10 \%$ ). It is clear from the spatial distribution that ice cloud is uncommon over the majority of the southern African region in September. For the purpose of this study ice clouds are not included in the multi-column radiative transfer model. The presence of high ice clouds would act to reduce the magnitude of the direct radiative effect of any underlying biomass burning aerosol.

The effect of the diurnal variation of cloud amount and optical properties in the southern African region in September is also investigated. The majority of this work uses a four year mean cloud field derived from the Terra satellite, the orbit of which passes from North to South across the equator in the morning. The cloud field included in the model is therefore biased towards clouds present during the morning. The recent addition of the MODIS Aqua satellite with an orbit that overpasses the equator from South to North in the afternoon will dramatically increase the ability to monitor the daily variability of the atmosphere. Figure 6 shows the percentage change from the Terra (morning overpass) to Aqua (afternoon overpass) data of $\tau_{c l o u d}, r_{\text {eff }}$, and water cloud fraction for September (2002-2003 average). A positive value represents an increase during the day whilst a negative value represents a decrease. It is clear that the $\tau_{\text {cloud }}$ and cloud fraction tends to decrease over oceanic regions during the day. This decrease is consistent with visual observations of the stratocumulus cloud sheet off the coast of Namibia and Angola from the C-130 aircraft during SAFARI 2000. It is also in agreement with ship based observations of marine stratiform clouds (Rozendaal et al., 1995) and is likely a result of the increase in solar heating during the day tending to "burn-off" the low-level cloud (e.g. Johnson et al., 2004). Over land regions increases in the $\tau_{\text {cloud }}$ and cloud fraction during the day are evident. This is possibly 

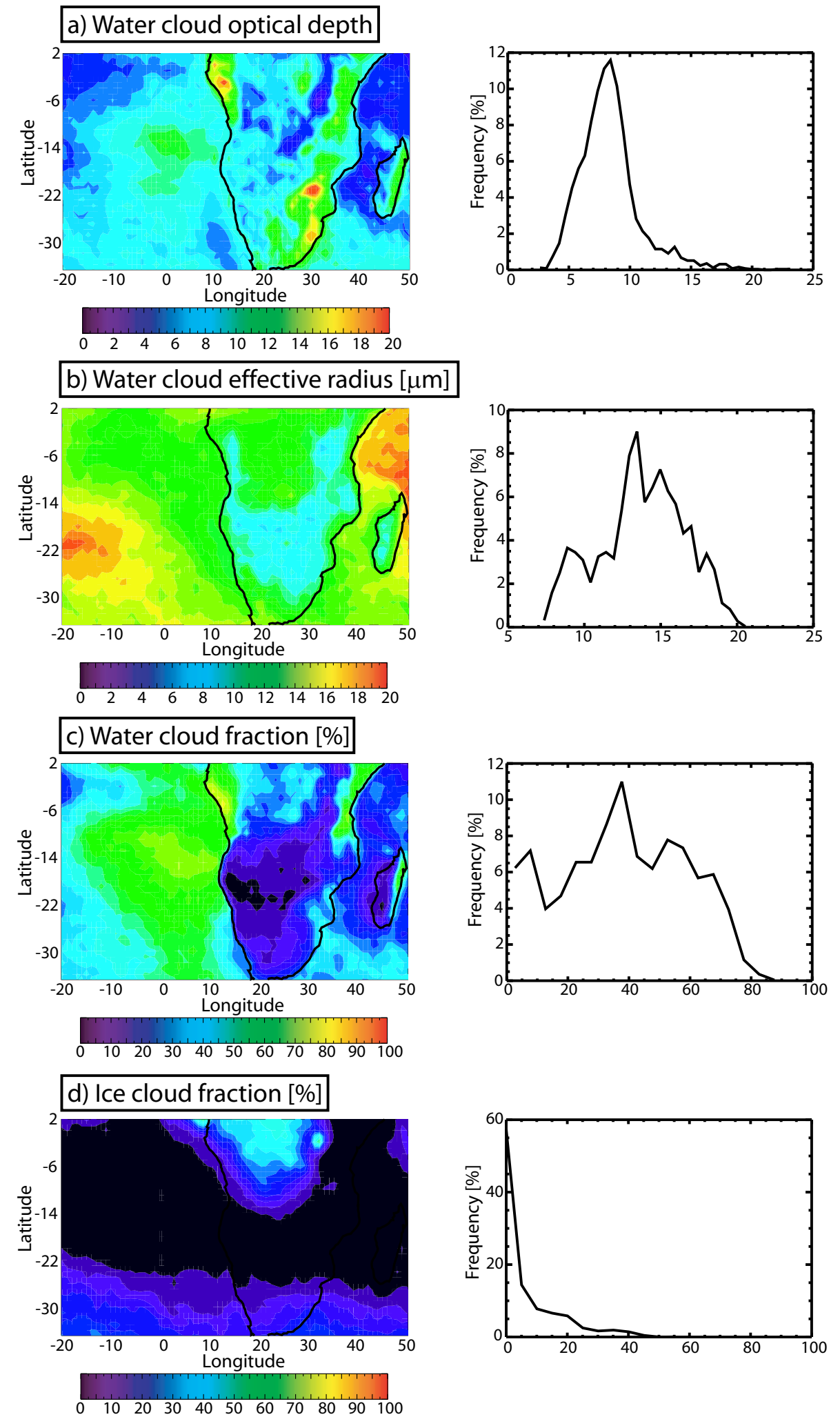

Fig. 5. MODIS Terra cloud products over southern Africa at $1 \times 1^{\circ}$ resolution for September (2000-2003 average). The spatial distribution and histograms are shown for (a) water cloud optical depth; (b) water cloud droplet effective radius [ $\mu$ m]; (c) water cloud fraction [\%]; (d) ice cloud fraction [\%]. The cloud optical depth and effective particle radius are averaged over data points where the water cloud fraction is greater than $0 \%$. 


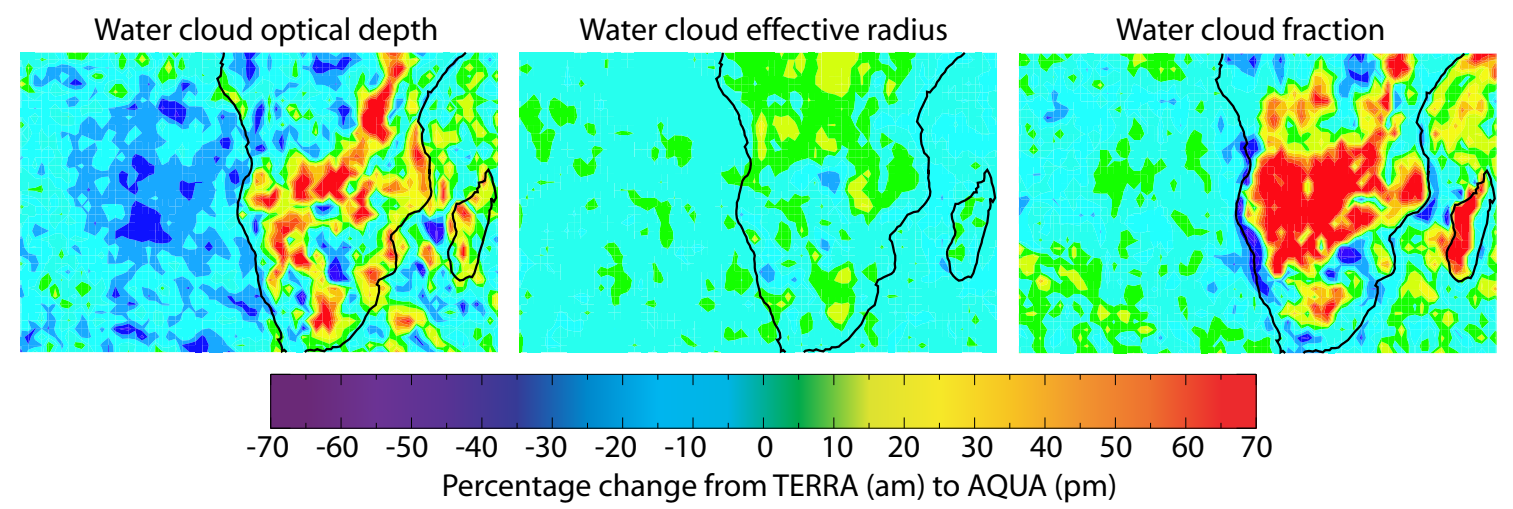

Fig. 6. The diurnal cycle of water cloud properties from the MODIS Terra (morning) and Aqua (afternoon) measurements in September (2002-2003 average). Positive values indicate an increase from morning to afternoon and negative values a decrease.

the result of an increase in convective activity. Differences between the Terra and Aqua measurements of $r_{e f f}$ are fairly small over both land and oceanic regions. To test the impact of the cloud diurnal cycle on the direct radiative effect of the biomass smoke, model runs are also performed using the two year mean cloud field derived from the Aqua satellite in Sect. 3.3.

\subsection{Vertical distribution of aerosol and cloud}

The typical vertical profiles of biomass burning aerosol and cloud measured on the C-130 aircraft during SAFARI 2000 were included in the radiative transfer model. The measurements show that the aerosol tended to be well mixed in the continental boundary layer over land (altitudes $<4.5 \mathrm{~km}$ ) due to strong dry convection (Haywood et al., 2003a,b), whereas over oceanic regions the aerosol existed in an elevated polluted layer (approximately $1.5-5.5 \mathrm{~km}$ above sea level) above a shallow marine boundary layer (MBL) (Keil and Haywood, 2003; Haywood et al., 2004). Similar vertical structures of biomass burning aerosol over land and oceanic regions have been measured with other instrument platforms in the southern African region (Anderson et al., 1996; Kaufman et al., 2003; Magi et al., 2003; Schmid et al., 2003). The aircraft measurements show that over oceanic regions the low-level cloud tends to form at the top of the MBL below the elevated biomass plume (Haywood et al., 2004). Over land the cloud was observed to form at the top of the continental boundary layer. Aerosol particles and cloud droplets are assumed to be externally mixed when they exist in the same model layer and changes in the aerosol optical properties with adsorption of water or any aerosol indirect effect on the cloud properties is neglected. In Sect. 3.4 the impact of changing the vertical profile on the direct radiative effect of the biomass smoke is investigated.

\subsection{Surface albedo}

Determination of the magnitude and sign of the direct radiative effect of aerosols on climate is highly sensitive to the prescribed surface albedo (e.g. Haywood and Shine, 1995; Ross et al., 1998; Myhre et al., 2003). A large number of GCMs currently adopt a land cover classification scheme for the parameterization of the surface albedo, which in turn requires an accurate representation of the soil and vegetation system (e.g. Sellers et al., 1996). However, recent advances in satellite based retrievals allow a long term consistent global and high spatial resolution data set of surface albedo to be derived. In this study, the sensitivity of the direct radiative effect of southern African biomass burning aerosol to the surface albedo derived from the Advanced Very High Resolution Radiometer (AVHRR) and MODIS satellites is investigated.

Both the AVHRR and MODIS satellites follow a similar methodology to convert the measured clear-sky up-welling reflectances at the TOA to a land surface albedo. The method involves converting the measured directional reflectances to a hemispheric albedo by utilizing models of the land bidirectional reflectance functions, an atmospheric correction to account for aerosol and water vapour effects, and a narrow to broadband spectral conversion.

The current operational MODIS surface albedo algorithm is discussed in detail in Jin et al. (2003a,b). The retrieval outputs seven spectral narrowband albedos $(\lambda=470,555,648$, $858,1240$, and $2130 \mathrm{~nm})$ and three broadband albedos, one in the visible $(0.3-0.7 \mu \mathrm{m})$, one in the near infra-red $(0.7$ $5.0 \mu \mathrm{m})$, and one covering both the visible and near infra-red range $(0.3-5.0 \mu \mathrm{m})$. Furthermore, both black-sky and whitesky albedos are reported at each spectral resolution. The black-sky albedo refers to the case where the surface is only illuminated by the direct component of the radiation whereas the illuminating radiation field in the white-sky albedo represents the diffuse component. These are both intrinsic albedos that depend on the reflectance properties of the surface. The 

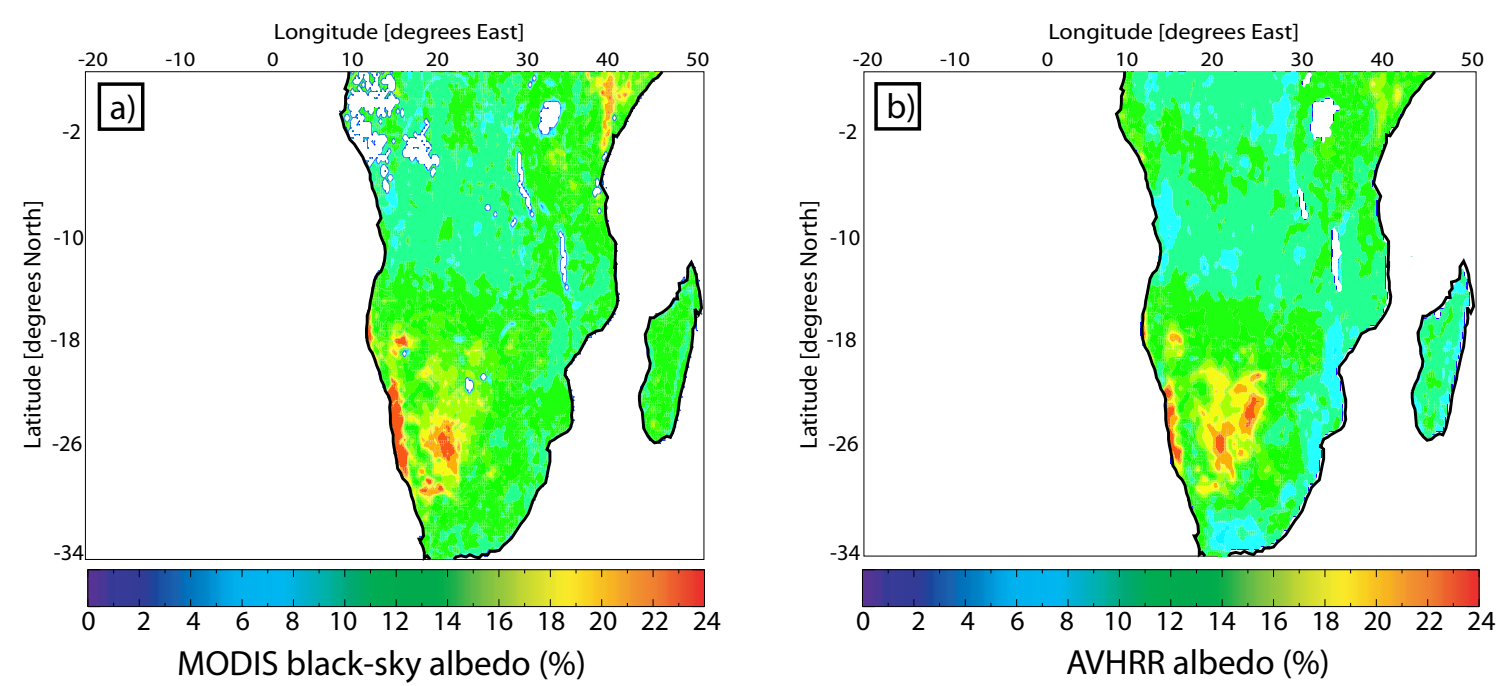

Fig. 7. (a) MODIS black-sky albedo $(0.3-5.0 \mu \mathrm{m})$ at $0.25^{\circ}$ resolution for the period $14-29$ September 2001 and (b) AVHRR albedo (0.35$3.0 \mu \mathrm{m})$ at $0.25^{\circ}$ resolution for September averaged over a five year period (1985-1987, 1989-1990). White pixels over land regions in the MODIS data set represents missing data values.

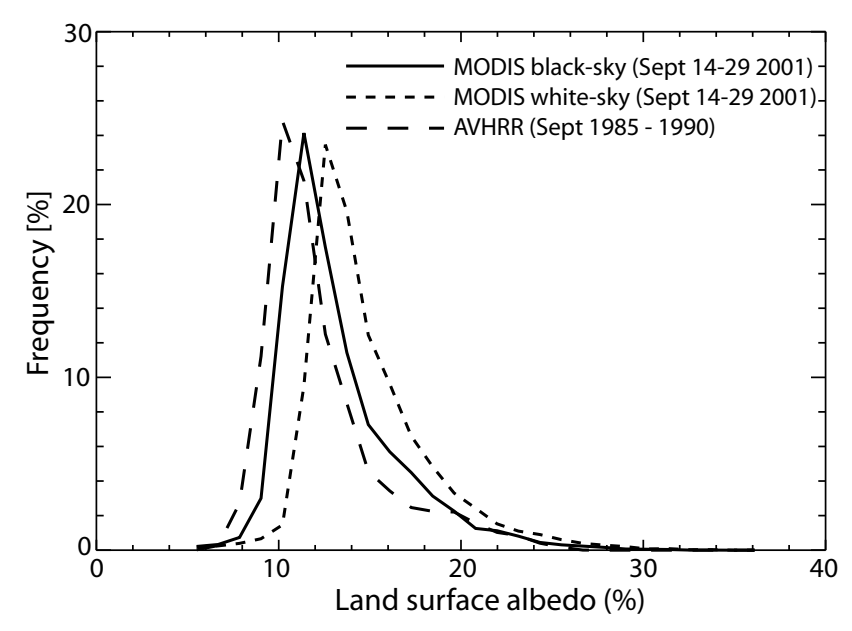

Fig. 8. Histograms of land surface albedo at $0.25^{\circ}$ resolution for southern Africa for the MODIS black and white-sky $(0.3-5.0 \mu \mathrm{m})$, and AVHRR $(0.35-3.0 \mu \mathrm{m})$ albedo retrievals. The bin size in the histogram is $1.2 \%$.

actual albedo that occurs in nature is a combination of the two and is dependent on the atmospheric illumination conditions. At the time of this study a long term data set of the MODIS surface albedo product was not available and so the $0.25^{\circ}$ resolution MOD43 16 day average product covering the period from 14-29 September 2001 is used. However, inclusion of the MODIS data into the radiative transfer model allows the effect that the increase in spectral complexity of the surface has on the radiative impact of the biomass burning aerosols to be investigated.
A detailed description of the AVHRR retrieval is given by Gutman et al. (1995) and Csiszar and Gutman (1999). The data set used in this study reports five year averaged values (September 1985-1987, 1989-1990), and contains the direct component of the albedo (similar to the MODIS black-sky albedo) in a broadband covering the spectral range 0.35$3.0 \mu \mathrm{m}$ at a resolution of $0.25^{\circ}$. A comparison with the MODIS broadband albedo will give insight into the effect that differences in the two retrievals, and perhaps changes in the surface albedo with time have on the radiative transfer calculations.

Figure 7 compares the broadband MODIS black-sky albedo over the southern African region to the broadband AVHRR albedo. Similar spatial patterns in the different retrievals of the direct component of the land surface albedo are evident. However, significant differences in the two retrievals can be seen by examination of the histograms in Fig. 8, with the albedo from the MODIS retrieval being larger in general. This is consistent with the results of Jin et al. (2003b), who compare the two albedos over the whole globe and attribute the difference to i) the direct component of the albedo generally being higher as the solar altitude increases due to the reflectance properties of the surface (the MODIS black-sky albedo is normalized to local-solar noon whereas the AVHRR albedo is normalized to an overhead Sun); ii) a possible residual aerosol effect in the AVHRR data due to an underestimation of the aerosol amount in the retrievals atmospheric correction procedure; iii) a change in the land cover from the historical AVHRR data-set to the more recent MODIS observations. Differences may also arise from the broadband retrievals of the two satellites covering different spectral ranges. The possible explanations are not investigated here, rather it is the resulting uncertainty in the 
modeled direct radiative effect to the different satellite retrievals of surface albedo that is of interest. It is also clear in Fig. 8 that the MODIS white-sky albedo (isotropic illumination) is greater than the MODIS black-sky albedo (direct illumination). The higher albedo results from an increase in the path length of a photon through the atmosphere and therefore a greater probability of multiple surface-atmosphere scattering with isotropic illumination compared to direct illumination at local solar noon.

Figure 9 shows the different spectral complexities available in the MODIS retrieval for the model grid box centred at $-22^{\circ} \mathrm{N}$ and $20^{\circ} \mathrm{E}$. The seven spectral narrowband retrievals show that there is an increase in the land surface albedo with wavelength to $\backsim 2 \mu \mathrm{m}$, highlighting the strong spectral dependence of the land surface reflectance. A 220 band spectral albedo is constructed at each model grid box by performing a quadratic fit to the seven spectral measurements in the wavelength range $0.47-2.13 \mu \mathrm{m}$. Outside of the wavelength range covered by the retrieval the albedo is extrapolated at a fixed value. Also indicated are the three different broadband retrievals. In Sect. 3.5 the effect of including either the broadband $(0.3-5.0 \mu \mathrm{m})$, the visible (VIS) and near infra-red (NIR) broadbands, or a 220 band spectral albedo to the radiative effect of the biomass smoke is explored.

In the radiative transfer model used in this study, both diffuse and direct components of surface albedo can be included. The ratio of the downwelling direct/diffuse radiation to the total downwelling radiation at the surface in the model is used to weight the individual direct/diffuse albedo components respectively. The inclusion of cloud or aerosol in the atmospheric column will therefore increase the relative weighting of the diffuse albedo. It should be noted that for the AVHRR albedo only a single direct broadband retrieval is available and so the diffuse component is set equal to the direct component. Interpolation to data missing regions in the MODIS data-set over land due to non clear sky conditions is performed before inclusion into the model. Over oceanic regions the surface albedo is set equal to $4 \%$ at all wavelengths in both data sets and is in agreement with the C-130 aircraft broadband measurements of Glew et al. (2005) for the relevant monthly mean solar altitude over southern Africa. The strong SZA dependence of the sea surface reflectance is not accounted for in this study.

\section{Results}

Base case calculations were performed with both the MODIS and GCM derived distributions of aerosol optical depth. Each model run included the fresh aerosol optical properties at the grid boxes where the total number of fire counts exceeds 500, and aged regional haze optical properties elsewhere, MODIS broadband $(0.3-5.0 \mu \mathrm{m})$ direct and diffuse land surface albedo, MODIS water cloud properties and spatial distribution from the Terra satellite, and the vertical

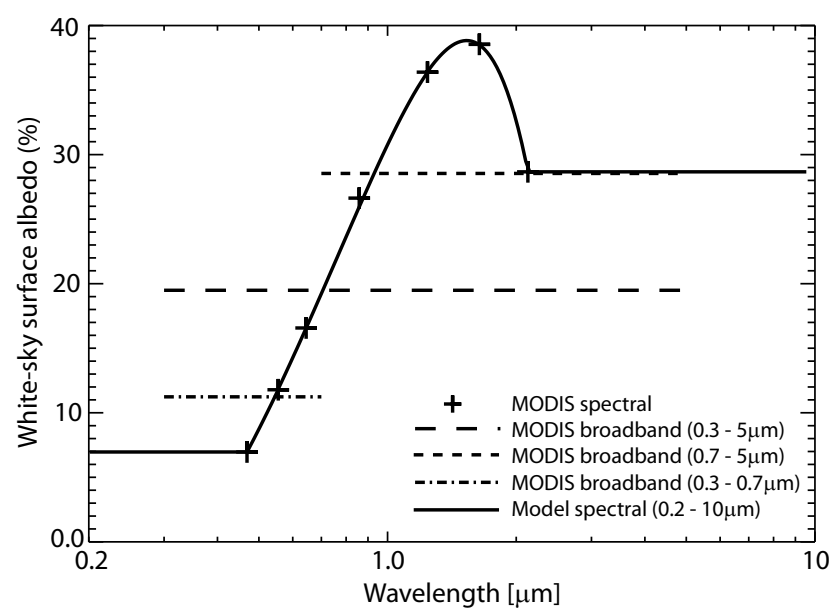

Fig. 9. MODIS white-sky albedo as a function of wavelength for 14-29 September 2001 aggregated to the model resolution $\left(4 \times 5^{\circ}\right)$ for the grid box centred at $-22^{\circ} \mathrm{N}, 20^{\circ} \mathrm{E}$. Shown are the three broadband retrievals at $0.3-0.7 \mu \mathrm{m}, 0.7-5 \mu \mathrm{m}, 0.3-5 \mu \mathrm{m}$, and the spectral dependent albedo derived from seven of the MODIS wavebands. Also indicated is the spectral albedo included in the model using least squares fitting with a quadratic of the form $y=a+b x+c x^{2}$ to the spectral measurements at $\lambda=0.47-2.13 \mu \mathrm{m}$, and extrapolated at a constant value for wavelengths outside of this range.

profile measured onboard the C-130 aircraft over land and oceanic regions. The horizontal resolution of the model was set at the resolution of the GCM aerosol data $\left(4 \times 5^{\circ}\right)$. The finer resolution of the other data sets were aggregated to the coarser resolution of the GCM. This allowed a direct comparison of the results from both of the aerosol distributions. At each grid point, the model time-step was set at $1 \mathrm{~h}$ and run over a $24 \mathrm{~h}$ period for the middle day of September. The incoming insolation at the TOA and SZA used to calculate the fluxes at each time-step are determined using the scheme employed in the Met Office Unified model (Ingram et al., 1997). The output model fluxes are then averaged over the total number of time-steps. Sensitivity tests were performed by running the model for the whole of September (computational time increased $\times 30$ ), resulting in minor differences $(\leq 1 \%)$ in the results presented. In the following analysis, the radiative forcing is defined as the instantaneous change in the net downwelling irradiance caused by the direct aerosol effect.

\subsection{Base case: sensitivity to aerosol spatial distribution}

Figure 10 shows the radiative forcing at the top of atmosphere $\left(\triangle F_{T O A}\right)$ for model runs with clouds not included (clear-sky) and with the inclusion of clouds (whole-sky) over the southern African region using the base case with the MODIS and GCM derived horizontal distributions of biomass burning aerosol. The clear-sky $\triangle F_{T O A}$ is negative everywhere and the spatial pattern is similar to the aerosol 


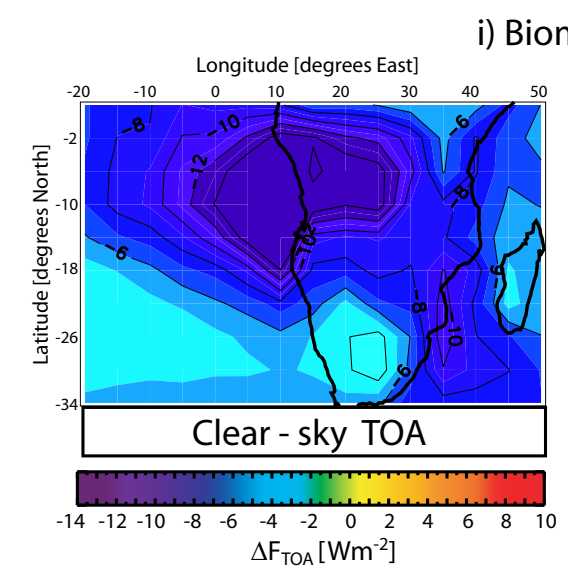

i) Biomass burning aerosol $=$ MODIS distribution
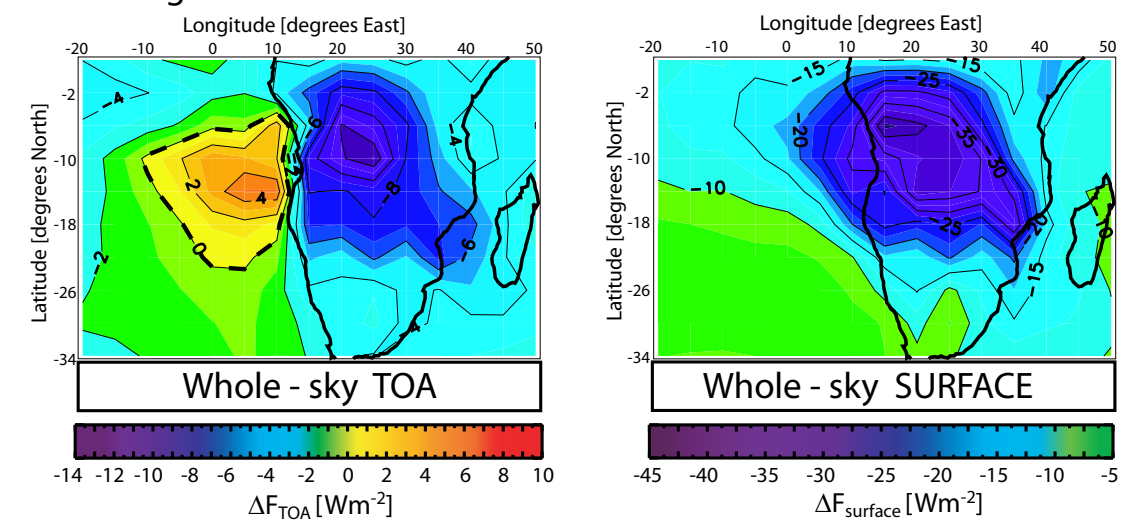

ii) Biomass burning aerosol $=\mathrm{GCM}$ distribution
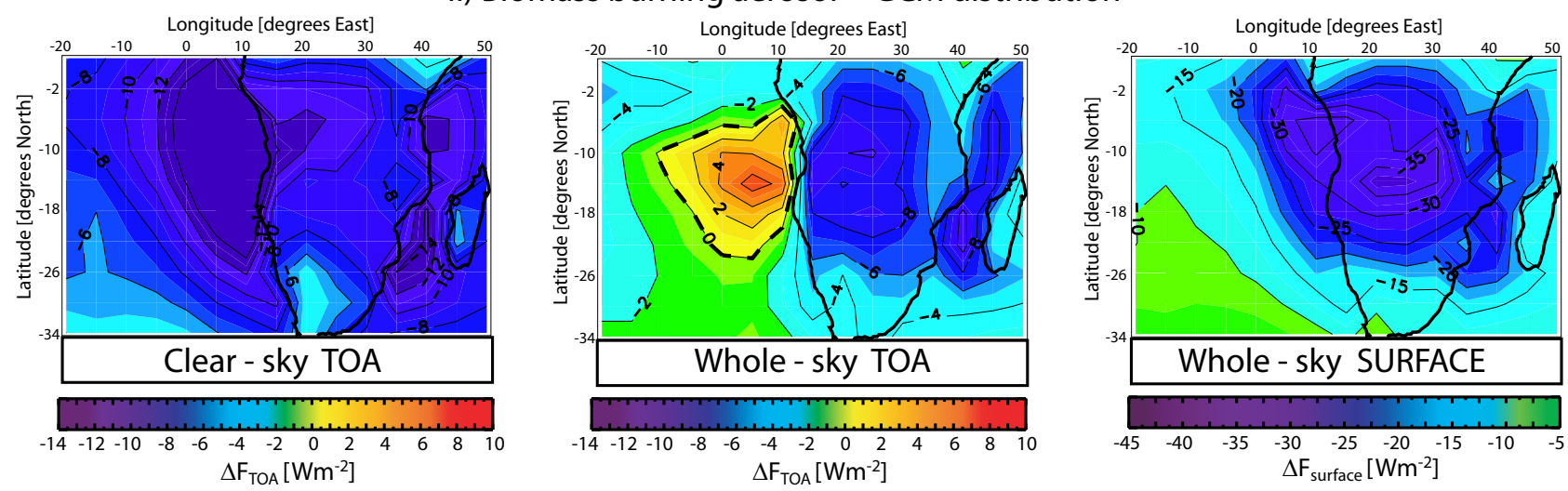

Fig. 10. Radiative impact over the southern African region in September using the base case with the biomass burning aerosol spatial distribution derived i) from the MODIS satellite aggregated to a resolution of $4 \times 5^{\circ}$, and ii) from the corrected model results of Tegen et al. (1997) at $4 \times 5^{\circ}$. Panels show $\Delta F_{T O A}$ under clear-sky conditions; $\Delta F_{T O A}$ with clouds included (whole-sky); $\Delta F_{\text {surface }}$ with clouds included (whole-sky). The dashed line indicates the transition between positive and negative radiative forcing. The color scale changes between the $\triangle F_{T O A}$ and $\Delta F_{\text {surface }}$ plots.

optical depth distribution included in the model, with the exception over the semi-arid regions to the south where the higher surface reflectance reduces the net outgoing flux at the TOA compared to areas with a lower surface albedo. The whole-sky model runs show a positive $\triangle F_{T O A}$ off the coast of Namibia and Angola where the partially absorbing aerosol overlies low-level cloud and is negative elsewhere. The region of positive forcing is in agreement with that predicted from the calculations of Keil and Haywood (2003). Also shown in Fig. 10 is the whole-sky radiative forcing at the surface $\left(\Delta F_{\text {surface }}\right)$, with large negative values evident over the whole of the southern African region.

Table 3 shows the average $\Delta F_{T O A}$ and $\Delta F_{\text {surface }}$ across the whole region, and the associated range in the grid box values of the radiative forcing, diagnosed from the different spatial distributions of biomass smoke. The average clear-sky $\triangle F_{T O A}$ varied between -7.6 to $-9.1 \mathrm{Wm}^{-2}$, and the $\Delta F_{\text {surface }}$ from -18.1 to $-21.4 \mathrm{Wm}^{-2}$ for the different aerosol distributions. In the absence of clouds the radiative impact at the surface is approximately 2.4 times greater compared to at the TOA. This ratio compares favourably with the results of Ichoku et al. (2003) $\left(\triangle F_{T O A}=-10 \mathrm{Wm}^{-2}\right.$, $\Delta F_{\text {surface }}=-26 \mathrm{Wm}^{-2}$ ), who use the MODIS aerosol optical depth data for September 2000 to determine the clear-sky forcing due to southern African biomass smoke over the Atlantic Ocean, and is also typical of studies over the Indian Ocean region (Satheesh and Ramanathan, 2000).

The average $\triangle F_{T O A}$ for whole-sky conditions ranges from -3.1 to $-3.6 \mathrm{Wm}^{-2}$, and the $\Delta F_{\text {surface }}$ from -14.4 to $-17.0 \mathrm{Wm}^{-2}$ depending on the aerosol distribution used, with the strongest radiative impact from the GCM derived optical depth. By comparing the clear-sky to the whole-sky runs it is clear that clouds reduce the direct radiative impact of biomass burning aerosol in the southern African region during September by a factor of approximately 2.5 at the TOA and 1.3 at the surface. The magnitude of the forcing is approximately 4.6 times greater at the surface compared to the TOA in the whole-sky runs. This is a direct consequence 
Table 3. September monthly mean surface and top of atmosphere direct radiative effect $\left[\mathrm{Wm}^{-2}\right]$ over the southern African region. Clear-sky and whole-sky results are shown for model runs including the spatial distribution of biomass smoke derived from the MODIS satellite and from the GCM data at $4 \times 5^{\circ}$ resolution. Also included is the range in the individual grid box values of radiative forcing over the model domain $\left[\mathrm{Wm}^{-2}\right]$.

\begin{tabular}{|c|c|c|c|c|c|c|c|c|}
\hline \multirow{2}{*}{$\begin{array}{l}\text { Aerosol } \\
\text { distribution }\end{array}$} & \multicolumn{4}{|c|}{ Clear-sky } & \multicolumn{4}{|c|}{ Whole-sky } \\
\hline & $\triangle F_{T O A}$ & Range & $\Delta F_{\text {surface }}$ & Range & $\triangle F_{T O A}$ & Range & $\Delta F_{\text {surface }}$ & Range \\
\hline MODIS & -7.6 & -3.2 to -21.6 & -18.1 & -7.8 to -57.6 & -3.1 & 5.1 to -13.1 & -14.4 & -5.9 to -43.5 \\
\hline GCM & -9.1 & -3.2 to -24.4 & -21.4 & -8.9 to -56.7 & -3.6 & 7.0 to -10.8 & -17.0 & -6.1 to -39.1 \\
\hline
\end{tabular}

of the large amount of solar radiation absorbed by the aerosol in the atmosphere which is given by $\triangle F_{T O A}-\Delta F_{\text {surface }}$, resulting in average values of 11.3 and $13.4 \mathrm{Wm}^{-2}$ for the two cases. This is similar to the value of $14 \pm 3 \mathrm{Wm}^{-2}$ reported for the Indian Ocean region during the dry season where large amounts of partially absorbing aerosol are persistent in a heavily polluted haze layer (Ramanathan et al., 2001). The strong reduction in the surface solar radiation (range in the grid box monthly mean $\Delta F_{\text {surface }}=-5.9$ to $-43.5 \mathrm{Wm}^{-2}$ ) must be compensated by a decrease in either the surface to atmosphere latent heat flux due to evaporation or to the sensible heat flux (Ramanathan et al., 2001). Reduction in the evaporation is likely to be significant over the oceanic regions and may result in a decrease in precipitation and a general weakening of the hydrological cycle over the southern African region. Due to the dry conditions over land in September the reduction in solar radiation is more likely to be compensated by changes in the sensible heat flux. The inclusion of realistic aerosol and cloud fields as used in this study into more detailed climate models would be needed to ascertain if these processes are likely to occur, and if so, assess the subsequent effect on regional climate.

Model runs were also performed using the uncorrected GCM aerosol distribution. This resulted in a large weakening of the modeled radiative forcing as a result of the large under estimation in the amount of aerosol. The impact was to reduce the average whole-sky $\Delta F_{T O A}$ to $-1.0 \mathrm{Wm}^{-2}$ and the $\Delta F_{\text {surface }}$ to $-4.1 \mathrm{Wm}^{-2}$, corresponding to changes from the base case of $-73 \%$ and $-76 \%$ for the TOA and surface forcings respectively. This highlights the large uncertainties in modeling the impact of aerosols on the climate system when utilizing models that do not simulate the emissions and transport of aerosols correctly.

The input parameters were then varied from the base case, and the sensitivity of the radiative forcing to each parameter determined. Table 4 summarizes the average radiative impact of the aerosol at the TOA and surface, the associated range in the individual grid box values of radiative forcing over the model domain, and the percentage change from the base case for various model runs using the MODIS aerosol distribution, whilst Fig. 11 shows the spatial distribution of the $\triangle F_{T O A}$ for a selection of the model runs. Identical features in the sensitivity of the radiative forcing were evident in model runs performed using the GCM aerosol distribution.

\subsection{Sensitivity to aerosol optical properties}

To assess the sensitivity in the radiative impact of the smoke from including one aerosol type in the model (fresh or aged) instead of identifying regions of persistent burning and including two types as in the base case, model runs were performed with the aerosol optical properties measured at the source and in the aged regional haze prescribed to the whole region. The net regional $\triangle F_{T O A}$ and $\Delta F_{\text {surface }}$ were found to be highly sensitive to the aerosol properties, with differences of $53 \%$ at the TOA and $26 \%$ at the surface between the fresh and aged aerosol only runs.

However, the spatial pattern in the radiative forcing is very similar between the base and aged aerosol cases (compare Figs. 11a and b), with differences of less than $\pm 3 \%$ in the regional forcing at both the TOA and surface. Much larger differences arise from the assumption of fresh aerosol everywhere. Figure $11 \mathrm{c}$ shows that the inclusion of the fresh aerosol at all grid boxes results in a larger region of positive $\triangle F_{T O A}$ over the southern Atlantic Ocean due to the presence of a more absorbing aerosol overlying the highly reflective cloud layer. This results in a significant weakening in the magnitude of the net regional impact of the biomass smoke at the TOA. In contrast, the excess absorption of the aerosol acts to further reduce the flux reaching the Earth's surface and therefore strengthens $\Delta F_{\text {surface }}$ when compared to the base case.

The sensitivity of the direct effect to the threshold value of satellite fire counts used to assign fresh aerosol properties to a grid box is tested by reducing the threshold from 500 (base case) to 300. This increases the surface area of the southern African region covered by fresh biomass smoke in the model from approximately 5 to $9 \%$ and results in a small weakening in the $\triangle F_{T O A}$ by $2 \%$. This suggests that the added complexity of including both fresh aerosol where burning is prevalent, and aged aerosol properties elsewhere does not significantly improve the estimation of $\Delta F_{T O A}$ and $\Delta F_{\text {surface }}$ on a regional scale compared to when using aged properties everywhere (3-5\% depending on the threshold value). 
Table 4. September monthly mean surface and top of atmosphere direct radiative effect $\left[\mathrm{Wm}^{-2}\right]$ over southern Africa for a series of models runs that vary the input parameters, using the MODIS derived horizontal distribution of biomass burning aerosol. Also shown is the percentage change from the base case monthly mean value, and the range in the individual grid box values of the radiative forcing [Wm ${ }^{-2}$ ] for each model run.

\begin{tabular}{|c|c|c|c|c|c|c|}
\hline \multirow[t]{2}{*}{ Difference from base case } & \multicolumn{3}{|c|}{ Top of atmosphere } & \multicolumn{3}{|c|}{ Surface } \\
\hline & $\Delta F$ & Change $(\%)$ & Range & $\Delta F$ & Change (\%) & Range \\
\hline None & -3.1 & $N / A$ & 5.1 to -13.1 & -14.4 & N/A & -5.9 to -43.5 \\
\hline \multicolumn{7}{|l|}{ Aerosol optical properties } \\
\hline Aged aerosol everywhere & -3.2 & +3 & 5.1 to -13.1 & -14.1 & -2 & -5.9 to -41.0 \\
\hline Fresh aerosol everywhere & -1.6 & -50 & 12.8 to -10.5 & -17.8 & +23 & -7.5 to -51.3 \\
\hline Fresh aerosol (fire counts $\geq 300$ ) & -3.0 & -2 & 5.1 to -12.1 & -14.7 & +2 & -5.9 to -49.2 \\
\hline \multicolumn{7}{|l|}{ Cloud optical properties } \\
\hline Cloud $r_{e f f}+1 \mu \mathrm{m}$ everywhere & -3.2 & +1 & 4.9 to -13.2 & -14.5 & $<1$ & -5.9 to -43.6 \\
\hline Cloud $r_{e f f}+3 \mu \mathrm{m}$ everywhere & -3.3 & +4 & 4.5 to -13.2 & -14.5 & +1 & -6.0 to -43.9 \\
\hline Cloud $\tau_{\text {cloud }} / 0.9$ everywhere & -2.9 & -8 & 6.6 to -13.0 & -14.2 & -1 & -5.8 to -42.6 \\
\hline Cloud $\tau_{\text {cloud }} / 0.7$ everywhere & -2.3 & -26 & 9.9 to -12.8 & -13.7 & -5 & -5.4 to -40.4 \\
\hline \multicolumn{7}{|l|}{ Cloud diurnal cycle } \\
\hline AQUA cloud field & -3.6 & +14 & 1.9 to -11.7 & -14.7 & +2 & -6.4 to -44.4 \\
\hline \multicolumn{7}{|l|}{ Vertical structure } \\
\hline Aerosol and cloud land profile everywhere & -4.8 & +53 & -2.3 to -13.1 & -14.6 & +2 & -6.0 to -43.5 \\
\hline Aerosol and cloud oceanic profile everywhere & -2.1 & -32 & 12.7 to -11.1 & -14.2 & -2 & -5.9 to -40.2 \\
\hline \multicolumn{7}{|l|}{ Surface albedo } \\
\hline AVHRR broadband surface albedo & -3.2 & +3 & 5.2 to -13.1 & -14.5 & $<1$ & -5.9 to -43.4 \\
\hline MODIS spectral surface albedo & -3.4 & +10 & 5.1 to -14.6 & -14.6 & +1 & -5.9 to -43.9 \\
\hline MODIS VIS and NIR broadband surface albedo & -3.5 & +12 & 5.1 to -15.2 & -14.7 & +2 & -5.9 to -44.1 \\
\hline
\end{tabular}

3.3 Sensitivity to cloud optical depth and optical properties

The MODIS satellite measurements of $\tau_{\text {cloud }}$ and $r_{\text {eff }}$ used in this study do not include aerosols in the retrieval algorithm. Haywood et al. (2004) demonstrate that a potential low bias exists in the MODIS data when biomass burning aerosols overlay low-level clouds, as is the case off the coast of Namibia and Angola. This bias may be as large as $-30 \%$ in $\tau_{\text {cloud }}$ and $-3 \mu \mathrm{m}$ in $r_{\text {eff }}$ depending on the burden and optical properties of the cloud and aerosol, and the wavelengths used in the retrieval. Model runs were performed with the $r_{\text {eff }}$ increased by 1 to $3 \mu \mathrm{m}$, and the $\tau_{\text {cloud }}$ corrected for a $10 \%\left(\tau_{\text {cloud }} / 0.9\right)$ and a $30 \%\left(\tau_{\text {cloud }} / 0.7\right)$ underestimation in cloud optical thickness across the whole region in order to assess the impact that any biases have on the radiative forcing of the biomass smoke.

Increasing the $r_{e f f}$ of the MODIS data decreases the cloud reflectivity. Hence, the radiative impact of the aerosol over land increases as more solar radiation passes through the cloud to the underlying aerosol, and over oceanic regions the positive forcing decreases due to a smaller probability of multiple scattering between the aerosol and cloud (Fig. 11d).
However, the impact on the radiative forcing to the changes in $r_{e f f}$ is small in comparison to the other parameters tested, with a strengthening of the average $\triangle F_{T O A}$ from 1 to $4 \%$, and of less than 1 to $1 \%$ in the $\Delta F_{\text {surface }}$, for an increase in $r_{\text {eff }}$ of 1 to $3 \mu \mathrm{m}$. An increase in $\tau_{\text {cloud }}$ leads to a greater probability of a photon being scattered back out of the cloud top, and so the impact on the forcing is of the opposite sign to an increase in $r_{\text {eff }}$. Figure 11e shows that the positive region of $\triangle F_{T O A}$ over the southern Atlantic Ocean expands significantly compared to the base case when compensating for a $30 \%$ low bias in $\tau_{\text {cloud }}$. The net regional effect is to decrease the average $\triangle F_{T O A}$ by 8 to $26 \%$ when compensating for a 10 to $30 \%$ low bias in cloud optical thickness. The sensitivity at the surface is less, with changes ranging from -1 to $-5 \%$.

The effect of the diurnal cycle of clouds on the direct radiative effect of the biomass smoke is investigated by replacing the water cloud spatial distribution and optical properties derived from the MODIS Terra satellite (morning overpass) used in the majority of this study with those derived from the MODIS Aqua satellite (afternoon overpass). Figure 11f shows that the general reduction in both cloud cover and $\tau_{\text {cloud }}$ over oceanic regions results in a reduction in the 

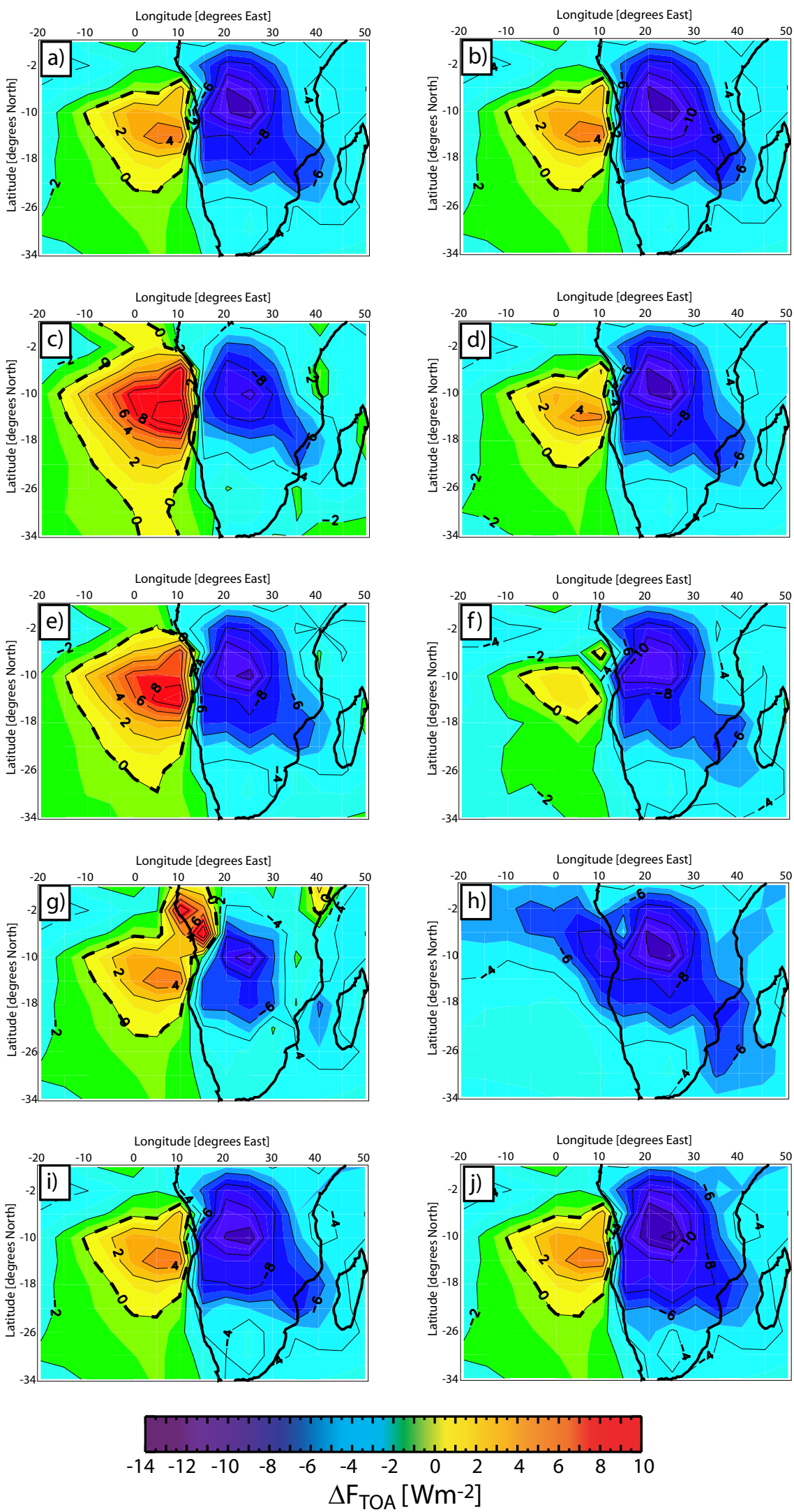

Fig. 11. The direct radiative forcing at the top of atmosphere (TOA) for a series of model runs using the spatial distribution of biomass burning aerosol derived from the MODIS satellite whilst perturbing other model inputs. The individual panels represent the (a) base case, (b) aged aerosol optical properties everywhere, (c) fresh aerosol optical properties everywhere, (d) cloud $r_{e f f}+3 \mu \mathrm{m}$ everywhere, (e) cloud $\tau_{\text {cloud }} / 0.7$ everywhere, (f) AQUA cloud field, (g) oceanic vertical profile everywhere, (h) land vertical profile everywhere, (i) AVHRR land surface albedo, and (j) MODIS derived 220 band spectral land surface albedo. 
positive $\triangle F_{T O A}$ of the overlying biomass smoke. Over land regions the $\triangle F_{T O A}$ becomes weaker due to an increase in cloud at the top of the biomass burning aerosol layer, although the impact of the cloud diurnal cycle is weaker than over oceanic regions due to the lower cloud fraction. The net effect is to increase the $\triangle F_{T O A}$ by $14 \%$, and by $2 \%$ in the $\Delta F_{\text {surface }}$ across the southern African region.

\subsection{Sensitivity to the vertical structure of aerosol and cloud}

The sensitivity to the vertical structure was examined by performing calculations with both the oceanic profile (aerosol above cloud level) and the land profile (aerosol in and below cloud level) applied to the whole region.

The average $\triangle F_{T O A}$ across the region decreased by $32 \%$ with application of the oceanic vertical structure. Figure $11 \mathrm{~g}$ shows that this is the result of the region of positive forcing off the West coast of southern Africa extending into land regions around the coast where cloud is prevalent. The magnitude of the forcing is also weakened further inland where the cloud amount is not large enough to result in a positive $\triangle F_{T O A}$. Substituting the vertical profile measured over land to the whole region resulted in an increase in the $\triangle F_{T O A}$ of $53 \%$. It can be seen in Fig. 11h that the presence of cloud at the top of the aerosol layer eliminates all of the areas of positive $\triangle F_{T O A}$, and so the impact of the biomass burning aerosol is to increase the outgoing flux at the TOA throughout the southern African region. This unrealistic vertical profile over oceanic regions gives similar results regarding the sign of the radiative forcing to the GCM results of Penner et al. (1998), Grant et al. (1999), and Iacobellis et al. (1999), highlighting the importance of accurately representing both aerosol and cloud fields in models when assessing the magnitude and sign of the direct aerosol effect at the TOA.

In contrast, the $\Delta F_{\text {surface }}$ is not sensitive to the vertical profile, with differences from the base case of $\leq 2 \%$ for both oceanic and land profiles. This is because the down-welling flux at the surface is mainly sensitive to the transmission of the overlying atmosphere which is largely independent on the vertical structure, whereas the fluxes at the TOA are sensitive to the radiation incident on the aerosol layer and the underlying reflectance. These in turn are highly dependent on the aerosol and cloud profile.

\subsection{Sensitivity to the land surface albedo}

The inclusion of the AVHRR broad-band land surface albedo (Fig. 11i) resulted in a strengthening of the $\triangle F_{T O A}$ by $3 \%$ when compared to the MODIS broad-band albedo used in the base case. This is the result of a lower probability of multiple surface-aerosol scattering due to the less reflective surface, leading to a smaller degree of aerosol absorption. Changes of less than $1 \%$ in the radiative impact were evident at the surface.
Application of the more detailed spectrally varying albedo (220 bands) derived from the fit to the seven wavelengths in the MODIS satellite retrieval resulted in a strengthening of the $\triangle F_{T O A}$ and the $\Delta F_{\text {surface }}$ by $10 \%$ and $1 \%$, respectively. This increase is a direct result of the high spectral dependence of the aerosol optical properties. Because the land surface albedo tends to be lower in the visible wavelength range (where the aerosol extinction coefficient is the largest) than at longer wavelengths, the surface is effectively less reflective than in the broad-band retrieval and therefore leads to less aerosol absorption in the atmosphere and a greater outgoing flux at the TOA (see Fig. 11j). This shows that the wavelength dependence of surface albedo plays an important role in determining the radiative impact of aerosols. The inclusion of the MODIS visible and near infra-red broadband albedo resulted in small differences of less than $2 \%$ in the $\triangle F_{T O A}$ compared to using the more detailed 220 band version, suggesting that the simple inclusion of a visible and near infra-red broadband albedo in climate models will improve the assessment of any direct aerosol radiative effect when compared to using a single broadband albedo.

\section{Conclusions}

In this study a multi-column radiative transfer code is used to model the direct radiative effect of biomass burning aerosols over the southern African region during September (peak of burning season). The input parameters included in the model are constrained by a variety of measurements and the most important parameters that need to be targeted by future observations and accurately captured in more detailed climate models are then determined.

The horizontal distribution of biomass burning aerosols were estimated from the GCM model results of Tegen et al. (1997) and from a four year data set of observations from the MODIS Terra satellite. The GCM distribution was found to severely under estimate the column integrated aerosol optical depth when compared to ground based and satellite observations, especially in the dry burning season. This under estimation is a common feature of many aerosol models in regions influenced by biomass smoke (Kinne et al., 2003). Correction factors were derived to compensate for the low bias in the model data and back-out the biomass smoke component. Through future multi-model and observational comparisons, improving the quality and thus reducing uncertainty in GCM aerosol simulations should be achieved and is a key objective of the AeroCom project (http://nansen.ipsl.jussieu.fr/AEROCOM/). By placing constraints on the spatial distribution of aerosol derived from observations, the aerosol distribution used in this study is likely to be less uncertain than in previous GCM studies of the radiative impact of biomass burning aerosols (e.g. Penner et al., 1998; Iacobellis et al., 1999; Myhre et al., 2003). 
The modeled clear-sky $\triangle F_{T O A}$ averaged over the southern African region ranged from -7.6 to $-9.1 \mathrm{Wm}^{-2}$, and the $\Delta F_{\text {surface }}$ from -18.1 to $-21.4 \mathrm{Wm}^{-2}$ for the MODIS and GCM derived aerosol fields (base case). The inclusion of clouds in the model reduced the radiative impact of the biomass smoke, resulting in an average $\triangle F_{T O A}$ of -3.1 to $-3.6 \mathrm{Wm}^{-2}$ and a $\Delta F_{\text {surface }}$ of -14.4 to $-17.0 \mathrm{Wm}^{-2}$. The corresponding absorption of solar radiation by the intervening atmosphere is 11.3 to $13.4 \mathrm{Wm}^{-2}$. This shows that the direct effect of southern African biomass burning aerosols can significantly alter the tropospheric and surface energy budgets, and may therefore influence the hydrological cycle and atmospheric circulation patterns (Ramanathan et al., 2001).

The sensitivity of the direct effect to the aerosol optical properties is primarily driven by differences in $\omega_{0}$, and hence the degree of absorption of short-wave radiation by the biomass burning aerosol. As a result of the rapid evolution in the aerosol $\omega_{0}$ downwind from emission sources (Abel et al., 2003), it was found that models can adequately simulate the mean regional direct effect of biomass smoke when the properties of aged aerosols are prescribed throughout the southern African region, whereas model simulations that included the optical properties of fresh smoke (lower $\left.\omega_{0}\right)$ everywhere resulted in a large underestimation in the $\triangle F_{T O A}$. This suggests that measurements of the optical properties of biomass burning aerosols taken near emission sources are of limited use when assessing the large scale radiative impacts of biomass smoke.

The vertical structure of biomass burning aerosols and clouds was critical in determining the magnitude (regional) and sign (local) of the $\triangle F_{T O A}$. Using realistic vertical profiles based on in situ measurements, sharp contrasts between areas of strong positive and negative $\triangle F_{T O A}$ were apparent. A large region of positive $\triangle F_{T O A}$ was calculated in this study over the southern Atlantic Ocean where the biomass smoke is advected above low level clouds, in agreement with the results of Keil and Haywood (2003). This is in contrast to the model studies considered by IPCC (2001), indicating that the vertical structure and/or cloud fields were not simulated well in those models. Current measurements of the vertical structure of aerosols and clouds are limited to aircraft and ground based measurements, and are therefore both spatially and temporally data sparse. The advent of spaceborne lidars such as the Cloud-Aerosol Lidar and Infrared Pathfinder Satellite Observations (CALIPSO) instrument (Winker et al., 2003) will enable the vertical profiles of tropospheric aerosols and clouds to be characterized on a global scale, providing a means of improving model simulations.

The $\triangle F_{T O A}$ was shown to be sensitive to the diurnal cycle of clouds and therefore needs to be well represented in climate models, particularly in regions where partially absorbing aerosols exist in elevated layers. The recent measurements from the polar orbiting MODIS Aqua satellite (afternoon overpass) will compliment the data from the MODIS
Terra satellite (morning overpass) in building up a global picture of the diurnal cycle of clouds, albeit limited to two measurements over an individual scene each day. The data from geostationary satellites, such as Meteosat 7, can provide high temporal information of clouds that are likely to be more useful in validating the diurnal cycle in models (e.g. Slingo et al., 2004).

The role of the land surface characteristics were examined by including the AVHRR and MODIS satellite retrievals of land surface albedo into the model at various spectral resolutions. The wavelength dependence of the surface reflectance was shown to play an important role in simulating the direct aerosol effect, and that the inclusion of a visible and near infrared broadband albedo improved the representation of the surface when compared to the inclusion of a single broadband retrieval. Future measurement campaigns should therefore examine the spectral dependency of surface albedo in order to both validate satellite based retrievals and to provide constraints for local column radiative closure studies.

Improving current model estimates of the direct radiative effect of biomass burning aerosols over southern Africa may be achieved by focusing future efforts on simulating the most important parameters revealed in the sensitivity study, which are prioritized as follows;

1. Horizontal distribution of aerosol optical depth.

2. Aerosol and cloud vertical structure, especially in the area of the Namibian cloud sheet.

3. Optical properties of the aerosol, particularly $\omega_{0}$.

4. Well simulated cloud fields, including cloud optical properties and diurnal cycle.

5. Spectral dependence of the land surface albedo.

Assimilation of satellite based aerosol products into models is now coming to the fore, and has been shown to improve the representation of aerosol optical depth in current models (Collins et al., 2001). As data assimilation techniques become more advanced, and future satellites observe the atmosphere in more detail, the technique should be used to improve the representations of the burden, vertical distribution, and optical properties of aerosols and clouds in both climate simulations and numerical weather prediction models, thereby reducing many of the large uncertainties in the radiative effects of aerosols and the resulting changes in the meteorology and climate. However, the potential uncertainties in spaceborne retrievals of atmospheric constituents must be borne in mind. For example, the potential low bias in cloud optical depth due to the neglect of overlying absorbing aerosols in the MODIS cloud retrieval algorithm (Haywood et al., 2004) may have led to an overestimation of the radiative forcing at the TOA in the model calculations presented in this study. Detailed in-situ aircraft and ground based measurements are therefore required to validate the operational 
satellite based retrievals under a wide range of atmospheric conditions.

Acknowledgements. We would like to thank the Meteorological Research Flight aircrew and support staff for their efforts during SAFARI 2000. B. Holben and S. Piketh and their staff are thanked for establishing and maintaining the 22 AERONET sites used in this investigation. The MODIS atmosphere data used in this study were acquired as part of the NASA's Earth Science Enterprise. The algorithms were developed by the MODIS Science Teams. The data were processed by the MODIS Adaptive Processing System (MODAPS) and Goddard Distributed Active Archive Center (DAAC), and are archived and distributed by the Goddard DAAC. The MODIS surface albedo data are distributed by the Land Processes Distributed Active Archive Center (LP DAAC), located at the U.S. Geological Survey's EROS Data Center. S. Abel would like to thank NERC and the Met Office for providing the CASE studentship under which this research was undertaken.

Edited by: B. Kärcher

\section{References}

Abel, S. J., Haywood, J. M., Highwood, E. J., Li, J., and Buseck, P. R.: Evolution of biomass burning aerosol properties from an agricultural fire in southern Africa., Geophys. Res. Lett., 30, 1783, doi:10.1029/2002GL017342, 2003.

Anderson, B. E., Grant, W. B., Gregory, G. L., Browell, E. V., Collins Jr., J. E., Sachse, G. W., Bagwell, D. R., Hudgins, C. H., Blake, D. R., and Blake, N. J.: Aerosols from biomass burning over the tropical South Atlantic region: Distributions and impacts, J. Geophys. Res., 101, 24 117-24 137, 1996.

Barbosa, P. M., Stroppiana, D., Grégoire, J. M., and Pereira, J. M. C.: An assessment of vegetation fire in Africa (19811991): Burned areas, burned biomass, and atmospheric emissions, Global Biogeochem. Cycles, 13, 933-950, 1999.

Boucher, O. and Haywood, J.: On summing the components of radiative forcing of climate change, Clim. Dyn., 18, 297-302, 2001.

Chin, M., Jacob, D. J., Gardner, G. M., Spiro, P. A., ForemanFowler, M., and Savoie, D. L.: A global three-dimensional model of tropospheric sulfate, J. Geophys. Res., 101, 18 677-18690, 1996.

Chu, D. A., Kaufman, Y. J., Ichoku, C., Remer, L. A., Tanré, D., and Holben, B. N.: Validation of MODIS aerosol optical depth retrieval over land, Geophys. Res. Lett., 29, 1617, doi:10.1029/2001GL013205, 2002.

Cofer III., W. R., Levine, J. S., Winstead, E. L., Cahoon, D. R., Sebacher, D. I., Pinto, J. P., and Stocks, B. J.: Source compositions of trace gases released during African savanna fires, J. Geophys. Res., 101, 23 597-23 602, 1996.

Collins, W. D., Rasch, P. J., Eaton, B. E., Khattatov, B. V., Lamarque, J.-F., and Zender, C. S.: Simulating aerosols using a chemical transport model with assimilation of satellite aerosol retrievals: Methodology for INDOEX, J. Geophys. Res., 106, 7313-7336, 2001.

Crutzen, P. J. and Andreae, M. O.: Biomass burning in the tropics: impact on atmospheric chemistry and biogeochemical cycles, Science, 250, 1669-1678, 1990.
Csiszar, I. and Gutman, G.: Mapping global land surface albedo from NOAA AVHRR, J. Geophys. Res., 104, 6215-6228, 1999.

Eck, T. F., Holben, B. N., Ward, D. E., Mukelabai, M. M., Dubovik, O., Smirnov, A., Schafer, J. S., Hsu, N. C., Piketh, S. J., Queface, A., Le Roux, J., Swap, R. J., and Slutsker, I.: Variability of biomass burning aerosol optical characteristics in southern Africa during the SAFARI 2000 dry season campaign and a comparison of single scattering albedo estimates from radiometric measurements, J. Geophys. Res., 108, 8477, doi:10.1029/2002JD002321, 2003.

Edwards, J. M. and Slingo, A.: Studies with a flexible new radiation code, Part 1. Choosing a configuration for a large-scale model, Quart. J. Roy. Met. Soc., 122, 689-719, 1996.

Giglio, L., Kendall, J. D., and Mack, R.: A multi-year active fire dataset for the tropics derived from the TRMM VIRS, Int. J. Remote Sensing, 24, 4505-4525, 2003.

Glew, M. D., Hignett, P., and Taylor, J. P.: Aircraft measurements of sea surface albedo, Meteorological Research Flight Technical Note 55, available from Met. Off., Exeter, UK, 2005.

Grant, K. E., Chuang, C. C., Grossman, A. S., and Penner, J. E.: Modeling the spectral optical properties of ammonium sulfate and biomass burning aerosols: parameterization of relative humidity effects and model results, Atmos. Envir., 33, 2603-2620, 1999.

Gutman, G., Tarpley, D., Ignatov, A., and Olson, S.: The enhanced NOAA global land dataset from the Advanced Very High Resolution Radiometer, Bull. Amer. Meteorol. Soc., 76, 1141-1156, 1995.

Haywood, J. M. and Shine, K. P.: The effect of anthropogenic sulfate and soot aerosol on the clear sky planetary radiation budget, Geophys. Res. Lett., 22, 603-606, 1995.

Haywood, J. M., Osborne, S. R., Francis, P. N., Keil, A., Formenti, P., Andreae, M. O., and Kaye, P. H.: The mean physical and optical properties of regional haze dominated by biomass burning aerosol measured from the C-130 aircraft during SAFARI 2000, J. Geophys. Res., 108, 8473, doi:10.1029/2002JD002226, $2003 \mathrm{a}$.

Haywood, J. M., Francis, P., Dubovik, O., Glew, M., and Holben, B.: Comparison of aerosol size distributions, radiative properties, and optical depths determined by aircraft observations and Sun photometers during SAFARI 2000, J. Geophys. Res., 108, 8471, doi:10.1029/2002JD002250, 2003b.

Haywood, J. M., Osborne, S. R., and Abel, S. J.: The effect of overlying absorbing aerosol layers on remote sensing retrievals of cloud effective radius and cloud optical depth., Quart. J. Roy. Met. Soc., 130, 779-800, 2004.

Holben, B. N., Eck, T. F., Slutsker, I., Tanré, D., Buis, J. P., Setzer, A., Vermote, E., Reagan, J. A., Kaufman, Y. J., Nakajima, T., Lavenu, F., Jankowiak, I., and Smirnov, A.: AERONET - A federated instrument network and data archive for aerosol characterization, Remote Sens. Environ, 66, 1-16, 1998.

Iacobellis, S. F., Frouin, R., and Somerville, R. C. J.: Direct climate forcing by biomass-burning aerosols: Impact of correlations between controlling variables, J. Geophys. Res., 104, 12031$12045,1999$.

Ichoku, C., Remer, L. A., Kaufman, Y. J., Levy, R., Chu, D. A., Tanré, D., and Holben, B. N.: MODIS observations of aerosols and estimation of aerosol radiative forcing over southern Africa during SAFARI 2000, J. Geophys. Res., 108, 8499, 
doi:10.1029/2002JD002366, 2003.

Ingram, W. J., Woodward, S., and Edwards, J.: Unified Model documentation paper no. 23: Radiation, available from Met. Off., Exeter, UK, 1997.

IPCC: Climate change 2001: The scientific basis. Third assessment of the Intergovernmental Panel on Climate Change (IPCC), edited by Houghton, J. T., Ding, Y., Griggs, D. J., Noguer, M., van der Linden, P. J., Dai, X., Maskell, K., and Johnson, C. A., Cambridge Univ. Press, New York, USA, 2001.

Jin, Y. F., Schaaf, C. B., Gao, F., Li, X. W., Strahler, A. H., Lucht, W., and Liang, S. L.: Consistency of MODIS surface bidirectional reflectance function and albedo retrievals: 1. Algorithm performance, J. Geophys. Res., 108, 4158, doi:10.1029/2002JD002803, 2003a

Jin, Y. F., Schaaf, C. B., Woodcock, C. E., Gao, F., Li, X. W., Strahler, A. H., Lucht, W., and Liang, S. L.: Consistency of MODIS surface bidirectional reflectance function and albedo retrievals: 2. Validation, J. Geophys. Res., 108, 4159, doi:10.1029/2002JD002804, 2003b.

Johnson, B. T., Shine, K. P., and Forster, P. M.: The semi-direct aerosol effect: Impact of absorbing aerosols on marine stratocumulus, Quart. J. Roy. Met. Soc., 130, 1407-1422, 2004.

Kaufman, Y. J., Tanré, D., Remer, L. A., Vermote, E. F., Chu, A., and Holben, B. N.: Operational remote sensing of tropospheric aerosol over land from EOS moderate resolution imaging spectroradiometer, J. Geophys. Res., 102, 17 051-17 067, 1997.

Kaufman, Y. J., Haywood, J. M., Hobbs, P. V., Hart, W., Kleidman, R., and Schmid, B.: Remote sensing of vertical distributions of smoke aerosol off the coast of Africa, Geophys. Res. Lett., 30, 1831, doi:10.1029/2003GL017068, 2003.

Keil, A. and Haywood, J. M.: Solar radiative forcing by biomass burning aerosol particles during SAFARI 2000: A case study based on measured aerosol and cloud properties., J. Geophys. Res., 108, 8467, doi:10.1029/2002JD002315, 2003.

King, M. D., Menzel, W. P., Kaufman, Y. J., Tanré, D., Gao, B.C., Platnick, S., Ackerman, S. A., Remer, L. A., Pincus, R., and Hubanks, P. A.: Cloud and aerosol properties, precipitable water, and profiles of temperature and water vapour from MODIS, IEEE Trans. Geosci. Remote Sensing, 41, 442-458, 2003.

Kinne, S., Lohmann, U., Feichter, J., Schulz, M., Timmreck, C., Ghan, S., Easter, R., Chin, M., Ginoux, P., Takemura, T., Tegen, I., Koch, D., Herzog, M., Penner, J., Pitari, G., Holben, B., Eck, T., Smirnov, A., Dubovik, O., Slutsker, I., Tanre, D., Torres, O., Mishchenko, M., Geogdzhayev, I., Chu, D. A. and Kaufman, Y.: Monthly averages of aerosol properties: A global comparison among models, satellite data, and AERONET data, J. Geophys. Res., 108, 4634, doi:10.1029/2001JD001253, 2003.

Liousse, C., Penner, J. E., Chuang, C., Walton, J. J., Eddleman, H., and Cachier, H.: A global three-dimensional model study of carbonaceous aerosols, J. Geophys. Res., 101, 19411-19432, 1996.

Magi, B. I. and Hobbs, P. V.: Effects of humidity on aerosols in southern Africa during the biomass burning season, J. Geophys. Res., 108, 8495, doi:10.1029/2002JD002144, 2003.

Magi, B. I., Hobbs, P. V., Schmid, B., and Redemann, J.: Vertical profiles of light scattering, light absorption, and single scattering albedo during the dry, biomass burning season in southern Africa and comparisons of in situ and remote senesing measurements of aerosol optical depths, J. Geophys. Res., 108, 8504,
doi:10.1029/2002JD002361, 2003.

McClatchey, R. A., Fenn, R. W., Selby, J. E. A., Volz, P. E., and Garing, J. S.: Optical properties of the atmosphere (3rd Edition), Air Force Cambridge Research Papers, 411, 1972.

Myhre, G., Bernsten, T. K., Haywood, J. M., Sundet, J. K., Holben, B. N., Johnsrud, M., and Stordal, F.: Modeling the solar radiative impact of aerosols from biomass burning during the Southern African Regional Science Initiative (SAFARI-2000) experiment, J. Geophys. Res., 108, 8501, doi:10.1029/2002JD002313, 2003.

Osborne, S. R., Haywood, J. M., Francis, P. N., and Dubovik, O.: Short-wave radiative effects of biomass burning aerosol during SAFARI 2000, Quart. J. Roy. Met. Soc., 130, 1423-1447, 2004.

Penner, J. E., Chuang, C. C., and Grant, K.: Climate forcing by carbonaceous and sulfate aerosols, Clim. Dyn., 14, 839-851, 1998.

Platnick, S., King, M. D., Ackerman, S. A., Menzel, W. P., Baum, B. A., Riédi, J. C., and Frey, R. A.: The MODIS cloud products: algorithms and examples from Terra, IEEE Trans. Geosci. Remote Sensing, 41, 459-473, 2003.

Ramanathan, V., Crutzen, P. J., Kiehl, J. T., and Rosenfeld, D. Aerosols, climate, and the hydrological cycle, Science, 294 2119-2124, 2001.

Remer, L. A., Kaufman, Y. J., Levin, Z., and Ghan, S.: Model assessment of the ability of MODIS top-of-atmosphere direct radiative forcing from smoke aerosols, J. Atmos. Sci., 59, 657-667, 2002a.

Remer, L. A., Tanré, D., Kaufman, Y. J., Ichoku, C., Mattoo, S., Levy, R., Chu, D. A., Holben, B., Dubovik, O., Smirnov, A., Martins, J. V., Li, R.-R., and Ahmad, Z.: Validation of MODIS aerosol retrieval over ocean, Geophys. Res. Lett., 29, 1618, doi:10.1029/2001GL013204, 2002b.

Ross, J. L., Hobbs, P. V., and Holben, B.: Radiative characteristics of regional hazes dominated by smoke from biomass burning in Brazil: closure tests and direct radiative forcing, J. Geophys. Res., 103, 31 925-31 941, 1998.

Rozendaal, M. A., Leovy, C. B., and Klein, S. A.: An observational study of diurnal variations of marine stratiform cloud, J. Climate, 8, 1795-1809, 1995.

Satheesh, S. K. and Ramanathan, V.: Large differences in tropical aerosol forcing at the top of the atmosphere and Earth's surface, Nature, 405, 60-63, 2000.

Schmid, B., Redemann, J., Russell, P. B., Hobbs, P. V., Hlavka, D. L., McGill, M. J., Holben, B. N., Welton, E. J., Campbell, J. R., Torres, O., Kahn, R. A., Diner, D. J., Helmlinger, M. C., Chu, D. A., Robles-Gonzalez, C., and de Leeuw, G.: Coordinated airborne, spaceborne, and ground-based measurements of massive thick aerosol layers during the dry season in southern Africa, J. Geophys. Res., 108, 8496, doi:10.1029/2002JD002297, 2003.

Sellers, P. J., Randall, D. A., Collatz, G. J., ans Berry, J. A., Field, C. B., Dazlich, D. A., Zhang, C., Collelo, G. D., and Bounoua, L.: A revised land surface parameterization (SiB2) for atmospheric GCMs, Part I: Model formulation, J. Climate, 9, 676705, 1996.

Slingo, A., Hodges, K. I., and Robinson, G. J.: Simulation of the diurnal cycle in a climate model and its evaluation using data from Meteosat 7, Quart. J. Roy. Met. Soc., 130, 1449-1467, 2004.

Smirnov, A., Holben, B. N., Eck, T. F., Dubovik, O., and Slutsker, I.: Cloud-screening and quality control algorithms for the AERONET database, Remote Sens. Environ., 73, 337-349, 
2000.

Tanré, D., Kaufman, Y. J., Herman, M., and Mattoo, S.: Remote sensing of aerosol properties over oceans using the MODIS/EOS spectral radiances, J. Geophys. Res., 102, 16971-16 988, 1997.

Tegen, I. and Fung, I.: Modeling of mineral dust in the atmosphere: Sources, transport, and optical thickness, J. Geophys. Res., 100, 18 707-18 726, 1995.
Tegen, I., Hollrig, P., Chin, M., Fung, I., Jacob, D., and Penner, J.: Contribution of different aerosol species to the global aerosol extinction optical thickness: Estimates from model results, J. Geophys. Res., 102, 23 895-23 915, 1997.

Winker, D. M., Pelon, J., and McCormick, M. P.: The CALIPSO mission: Spaceborne lidar for observation of aerosols and clouds, Proc. SPIE, 4893, 1-11, 2003. 